\title{
AFIP-2 Fabrication Summary Report
}

\author{
Glenn Moore
}

February 2010

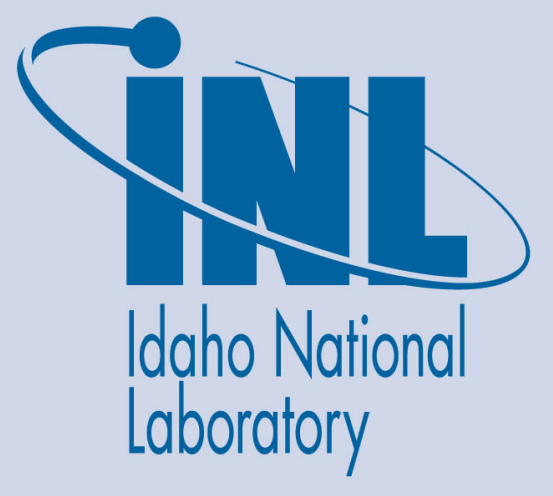

The INL is a U.S. Department of Energy National Laboratory operated by Battelle Energy Alliance 
INL/EXT-08-14871

\title{
AFIP-2 Fabrication Summary Report
}

\author{
Glenn Moore
}

February 2010

\section{Idaho National Laboratory \\ Idaho Falls, Idaho 83415}

http://www.inl.gov

Prepared for the

U.S. Department of Energy

Office of Nuclear Energy

Under DOE Idaho Operations Office

Contract DE-AC07-05ID14517 


\section{DISCLAIMER}

This information was prepared as an account of work sponsored by an agency of the U.S. Government. Neither the U.S. Government nor any agency thereof, nor any of their employees, makes any warranty, expressed or implied, or assumes any legal liability or responsibility for the accuracy, completeness, or usefulness, of any information, apparatus, product, or process disclosed, or represents that its use would not infringe privately owned rights. References herein to any specific commercial product, process, or service by trade name, trade mark, manufacturer, or otherwise, does not necessarily constitute or imply its endorsement, recommendation, or favoring by the U.S. Government or any agency thereof. The views and opinions of authors expressed herein do not necessarily state or reflect those of the U.S. Government or any agency thereof. 



\title{
AFIP-2 Fabrication Summary Report
}

\author{
INL/EXT-08-14871
}

February 2010
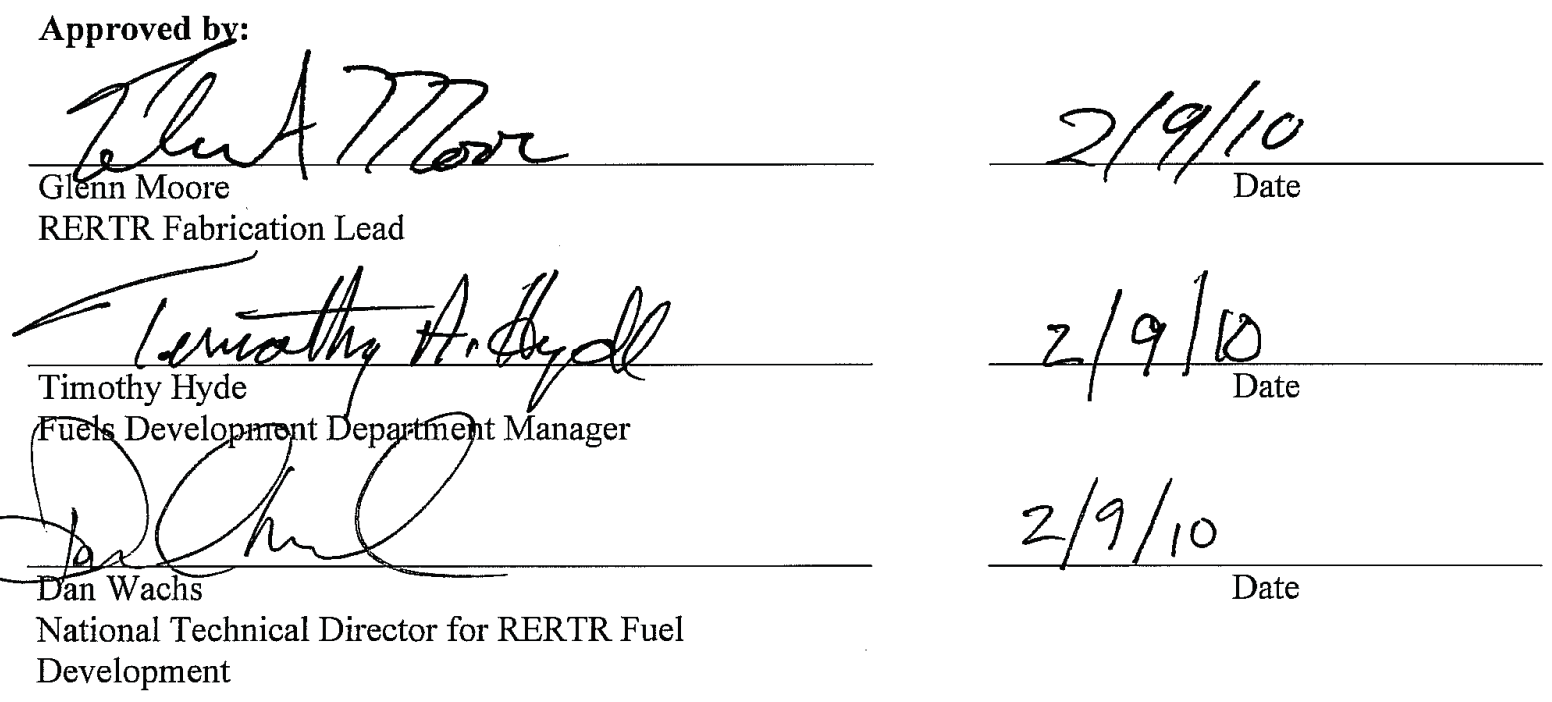



\begin{abstract}
The Advanced Test Reactor (ATR) Full-size Plate In Center Flux Trap Position (AFIP)-2 experiment was designed to evaluate the performance of monolithic fuels at a scale prototypic of research reactor fuel plates. Two qualified fueled plates were fabricated for the AFIP-2 experiment to be irradiated in the Idaho National Laboratory ATR. This report provides details of the fuel fabrication efforts, including material selection, fabrication processes, and fuel plate qualification.
\end{abstract}




\section{ACKNOWLEDGEMENTS}

The following people were instrumental in a successful AFIP-2 fabrication effort: Francine Rice, Doug Burkes, Jan Fong Jue, Jared Wight, Mike Chapple, Pat Hallinan, Blair Park, Steve Steffler, David Swank, Lonnie Haggard, Kristine Baker, Curtis Clark, David Cottle, Steven Taylor, Terri Dixon, Paul Wolf, and the MFC Quality Assurance Department. Work supported by the U.S.

Department of Energy (DOE), Office of Nuclear Nonproliferation and Security Affairs (NNSA) under DOE Office of Nuclear Energy, Science, and Technology Idaho Operations Office Contract DE AC07 05ID14517. 


\section{CONTENTS}

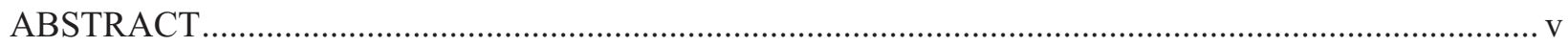

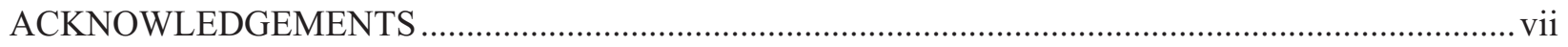

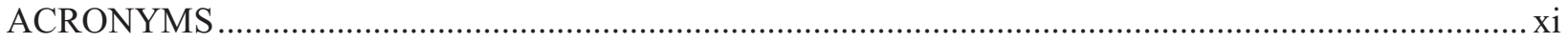

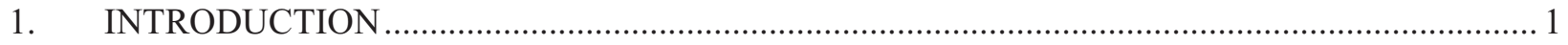

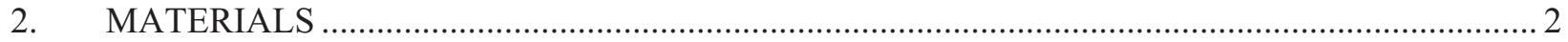

2.1 Cladding Material ................................................................................................ 3

2.2 Zirconium Diffusion Barrier Material................................................................................. 3

2.3 Silicon Thermal Spray Reaction Layer Powder .................................................................... 3

3. FOIL FABRICATION OF CO-ROLLED ZR FOILS........................................................... 3

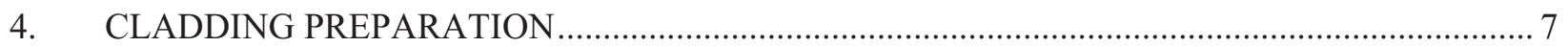

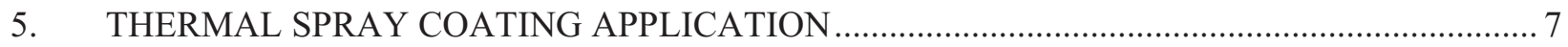

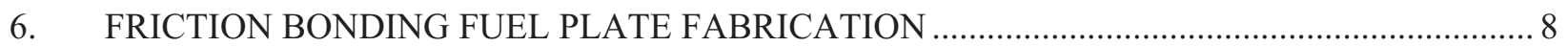

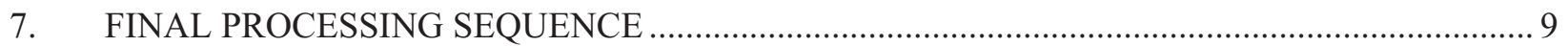

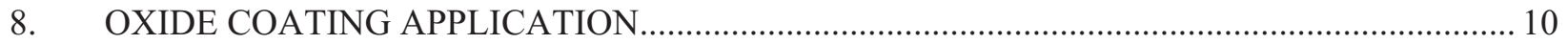

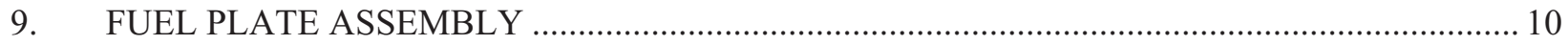

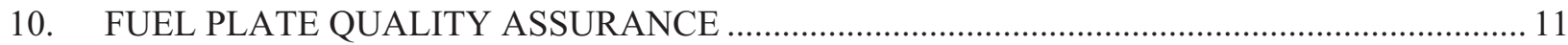

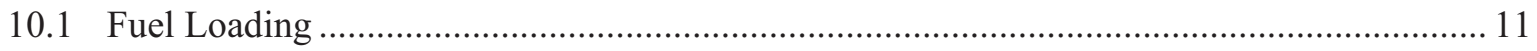

10.2 Collection and Processing of Densitometric Data................................................................. 11

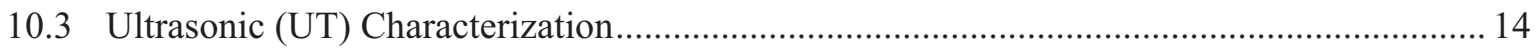

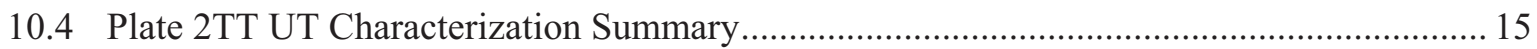

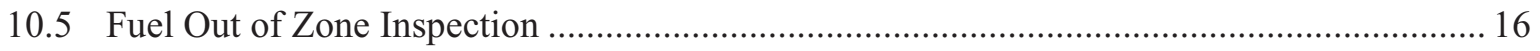

10.6 Dimensional, Surface, and Cleanliness Inspection …........................................................ 16

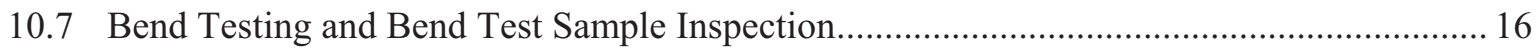

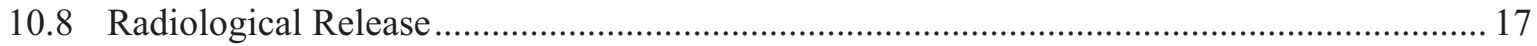

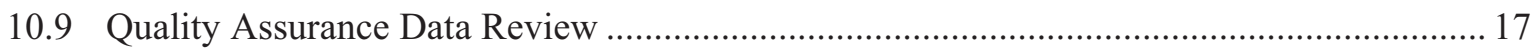

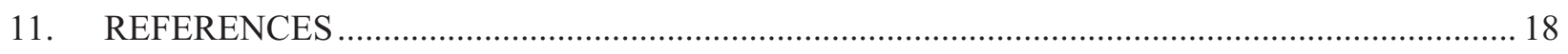

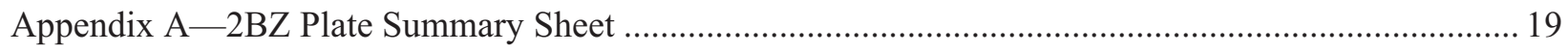

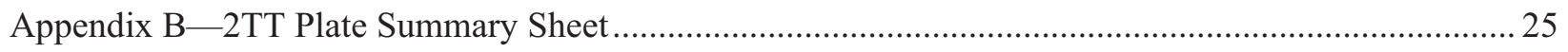




\section{FIGURES}

Figure 1. Image showing hot rolling assembly components prior to final lay-up and welding................. 4

Figure 2. Graph of rolling assembly thickness and pass force throughout $\mathrm{Zr}$ co-rolled U10Mo foil

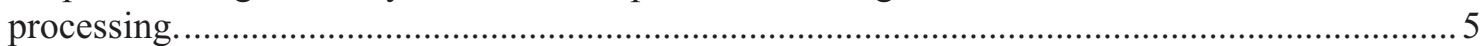

Figure 3. Hot rolling assembly post rolling and annealing, prior to foil removal.................................... 5

Figure 4. Sheared Zr co-rolled U10Mo fuel foil prior to cleaning........................................................... 6

Figure 5. Cross sectional scanning electron microscope (SEM) micrograph of a nominally 0.010in.-thick U10Mo fuel foil with $\mathrm{Zr}$ co-rolled barrier layer. ............................................................ 6

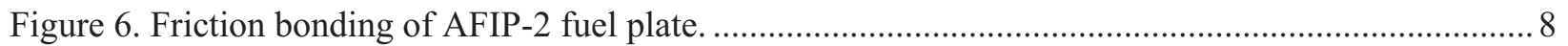

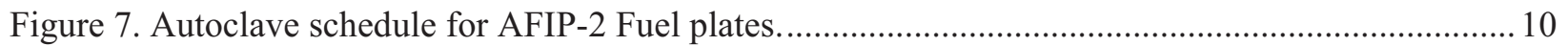

Figure 8. Composite image of AFIP-2 Experiment Fuel Plate Frame Assembly.................................... 10

Figure 9. Densitometric data acquisition map showing exposure and data collection scheme used

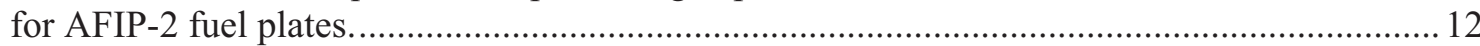

Figure 10. Example of Du8Mo standard data set plot and fit equation. .................................................. 12

Figure 11. Plot of calculated U10Mo thickness values for AFIP-2 fuel plate 2TT. ............................... 13

Figure 12. Plot of calculated U10Mo thickness values for AFIP-2 fuel plate 2BZ ............................... 13

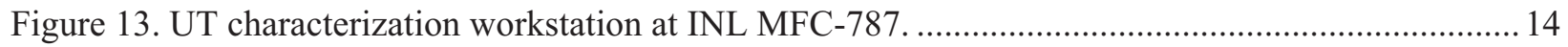

Figure 14. Debond scan images of AFIP-2 fuel plates....................................................................... 15

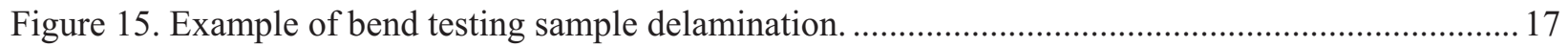

\section{TABLES}

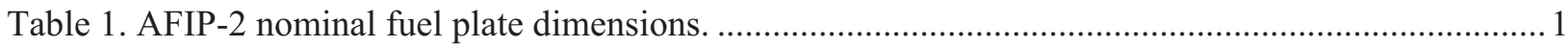

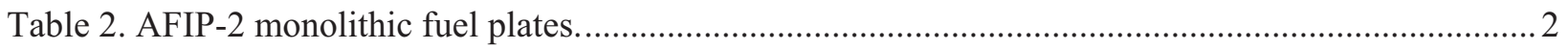

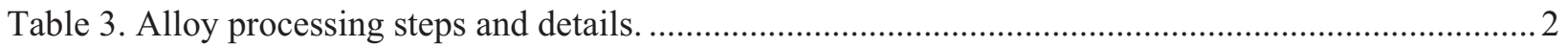

Table 4. Summary of Y-12 data for as-received U10Mo alloys incorporated into AFIP-2 fuel

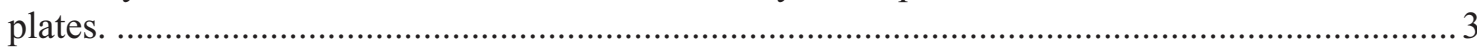

Table 5. Aluminum chemical cleaning processing steps and conditions.............................................. 7

Table 6. Friction bonding parameters used for the AFIP-2 fuel plate ................................................... 9

Table 7. Summary of fuel loading acceptance criteria and AFIP-2 plate data........................................ 11

Table 8. Summary of fuel loading thickness data for AFIP-2 fuel plates.............................................. 12

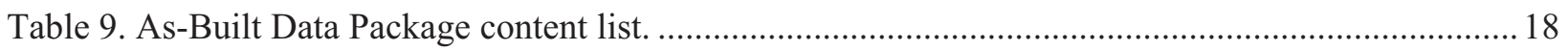




\section{ACRONYMS}

AFIP ATR Full-size Plate In Center Flux Trap Position

ATR Advanced Test Reactor

CNC Computer Numerically Controlled

DI deionized

DOE Department of Energy

FB Friction Bonding

FOZ Fuel out of Zone

ID Identification

INL Idaho National Laboratory

MFC Materials and Fuels Complex

NCR Non-Conformance Report

NNSA Office of Nuclear Nonproliferation and Security Affairs

OD optical density

PIE Post Irradiation Examination

QA Quality Assurance

RERTR Reduced Enrichment for Research and Test Reactors

SEM scanning electron microscope

Si silicon

UT ultrasonic testing

$\mathrm{Zr} \quad$ zirconium 


\section{AFIP-2 Fabrication Summary Report}

\section{INTRODUCTION}

The Advanced Test Reactor (ATR) Full-size Plate In Center Flux Trap Position (AFIP)-2 experiment was designed to evaluate the performance of monolithic fuels at a scale prototypic of research reactor fuel plates. Two qualified fueled plates were fabricated for the AFIP-2 experiment to be irradiated in the Idaho National Laboratory (INL) ATR. The plates were fabricated as described in INL PLN-2681, "Fabrication Control Plan for the AFIP-2 Experiment," at the INL Materials and Fuels Complex (MFC) by the Reduced Enrichment for Research and Test Reactors (RERTR) Fabrication Group from October 2007 to January 2008.

The AFIP-2 experiment consisted of two aluminum-clad monolithic fuel plates utilizing a metallic foil of U10Mo with 19.75\% U-235 enrichment. The cladding material used was aluminum 6061-T6. Table 1 summarizes the fuel plate dimensions, per INL Drawing 635788, "RERTR ATR Full Size Plate in Center Flux Trap Position Fuel Plate.”

Table 1. AFIP-2 nominal fuel plate dimensions.

\begin{tabular}{|l|c|c|}
\hline \multicolumn{1}{|c|}{ Dimension } & inches & $\mathrm{cm}$ \\
\hline Fuel Plate Length & 22.50 & 57.15 \\
\hline Fuel Plate Width & 2.21 & 5.61 \\
\hline Fuel Plate Thickness & 0.050 & 0.127 \\
\hline Fuel Foil Length & 20.65 & 52.45 \\
\hline Fuel Foil Width & 1.45 & 3.68 \\
\hline Fuel Foil Thickness & 0.014 & 0.036 \\
\hline
\end{tabular}

Based on the Post Irradiation Examination (PIE) of 1 in. $\times 4$ in. miniplate samples, it has been shown that a silicon-enhanced fuel/clad interface and a fuel/zirconium interface provide the chemical and mechanical stability desired in a fuel plate. Specifically, the addition of silicon to the fuel/clad interface by thermal spray techniques resulted in reduced fuel/matrix chemical interaction and increased stability of the interaction layer during irradiation; the observed behavior was very similar to that observed in dispersion fuels. It has also been observed that the interfaces between the uranium-molybdenum fuel, zirconium diffusion barrier, and cladding resulted in a very stable interface. Thus the AFIP-2 experiment included both fuel/clad interlayer compositions (Table 2).

This report provides details of the fuel fabrication efforts, including material selection, fabrication processes, and fuel plate qualification. 
Table 2. AFIP-2 monolithic fuel plates.

\begin{tabular}{|c|c|}
\hline Plate ID & Attributes \\
\hline $2 \mathrm{TT}$ & $\begin{array}{l}\text { - Uranium Molybdenum Fuel Alloy: U10Mo nominal } \\
\text { - Uranium Enrichment: } 19.75 \mathrm{wt} \% \mathrm{U} \text { enrichment nominal } \\
\text { - Fuel Meat Thickness: } 0.014 \text { in. nominal } \\
\text { - Cladding: } 6061 \text { aluminum in the T6 condition } \\
\text { - Other: Clad bonding via Friction Bonding process; } \sim 0.001 \text {-in.-thick silicon ( } \mathrm{Si}) \\
\text { thermal spray layer applied to cladding above and below fuel foil location. }\end{array}$ \\
\hline $2 \mathrm{BZ}$ & $\begin{array}{l}\text { - Uranium Molybdenum Fuel Alloy: U10Mo nominal } \\
\text { - Uranium Enrichment: } 19.75 \mathrm{wt} \% \text { U enrichment nominal } \\
\text { - Fuel Meat Thickness: } 0.014 \text { in. nominal } \\
\text { - Cladding: } 6061 \text { aluminum in the T6 condition } \\
\text { - Other: Clad bonding via Friction Bonding process; } \sim 0.001 \text {-in.-thick zirconium }(\mathrm{Zr}) \\
\text { layer applied to foil via hot rolling process on both sides of foil. }\end{array}$ \\
\hline
\end{tabular}

\section{MATERIALS}

The U10Mo fuel material was supplied by the Y-12 National Security Complex in the form of alloy foils and machined coupons. Both material forms were prepared at Y-12 as detailed in Table 3.

Table 3. Alloy processing steps and details.

\begin{tabular}{|l|l|}
\hline \multicolumn{1}{|c|}{ Alloy Processing Step } & \multicolumn{1}{c|}{ Details } \\
\hline Pre-Melt Casting & $\begin{array}{l}\text { Induction melting and casting of HEU, Low-Assay Diluent (DU), Alloy } \\
\text { Material (Mo) in proportion to yield U10Mo with nominally 19.75\% U-235 } \\
\text { enrichment. } \\
\text { Charge Size: } \sim 20 \mathrm{~kg} \text { performed twice with Mo adjustment on second cast. }\end{array}$ \\
\hline Final Casting & $\begin{array}{l}\text { Induction melting and casting of U10Mo alloy } \\
\text { Charge size: } \sim 5.8 \mathrm{~kg}, \text { casting dimensions: } 9.75 \text { in. long } \times 8 \text { in. wide } \times 0.190 \\
\text { in. thick }\end{array}$ \\
\hline Coupon Machining & Machined coupons $\sim 4.0$ in. long $\times \sim 2.5$ in. wide $\times \sim 0.090$ in. thick, $\sim 250 \mathrm{~g}$ \\
\hline Cold Rolling & $\begin{array}{l}\text { Four high rolling mill (schedule not disclosed) } \\
\text { Final Foil Thickness: } 0.014-0.017 \text { in. }\end{array}$ \\
\hline Foil Shearing & Cold-rolled foils sheared to $\sim 23$ in. long $\times 1.5$ in. wide \\
\hline
\end{tabular}

Summary data of the as-received U10Mo foil and coupon used to produce the 2TT and 2BZ fuel plates are summarized in Table 4 . The Y-12 provided chemical analysis/certification documentation can be found the INL Rec./Doc. ID 2600687: "RERTR AFIP-2 Irradiation Experiment in the ATR, As-Built Data Package, INL." 
Table 4. Summary of Y-12 data for as-received U10Mo alloys incorporated into AFIP-2 fuel plates.

\begin{tabular}{|c|c|}
\hline Item/Data & Value \\
\hline \multicolumn{2}{|l|}{ Foil: 3C19-WY-M9T9 used in fuel plate 2TT } \\
\hline Mo (wt $\%)$ & $10.21 \%$ \\
\hline Uranium Enrichment (wt\% U235) & $19.937 \%$ \\
\hline Carbon content (ppm) & 647 \\
\hline Weight & $119 \mathrm{~g}$ \\
\hline Length & 21.0 in. \\
\hline Width & 1.5 in. \\
\hline Average Thickness & 0.012 in. \\
\hline \multicolumn{2}{|l|}{ Coupon: 3C19-WY-M9YH used in fuel plate 2BZ } \\
\hline Mo (wt $\%)$ & $10.21 \%$ \\
\hline Uranium Enrichment (wt\% U235) & $19.881 \%$ \\
\hline Carbon content (ppm) & 647 \\
\hline Weight & $251.5 \mathrm{~g}$ \\
\hline Length & 4.0 in. \\
\hline Width & 2.5 in. \\
\hline Nominal Thickness & 0.09 in. \\
\hline
\end{tabular}

\subsection{Cladding Material}

The cladding material used for the AFIP-2 fuel plates was 6061aluminum in the T6 condition. Two thicknesses of aluminum sheet were utilized: 0.040 in. for the "bottom" foil-pocket cladding and 0.032 in. for the "top cover" cladding.

\subsection{Zirconium Diffusion Barrier Material}

Alfa Aesar Zirconium Foil, 0.25 mm (0.010 in.), 99.8\% metal basis

\subsection{Silicon Thermal Spray Reaction Layer Powder}

Praxiar Si-106 silicon powder, 99.9\% metal basis purity, sieve analysis: -100 mesh $=90-100 \%,-325$ mesh $=11-15 \%$

\section{FOIL FABRICATION OF CO-ROLLED ZR FOILS}

A $\mathrm{Zr}$ co-rolled fuel foil was used in the fuel plate " $2 \mathrm{BZ}$." The foil was processed from a cast and machined U10Mo coupon, nominally 4 in. long $\times 2.5$ in. wide $\times 0.090$ in. thick. The long dimension of the coupon was of vertical orientation with respect to the as-cast ingot.

In order to minimize the surface texture of the resulting foil, the coupon was cold rolled from an initial thickness of 0.088 in. to 0.085 in., via 24 cold rolling pass using a four high rolling mill. Prior to cold rolling, the alloy coupon was acid cleaned to remove any surface oxide/contamination. A 30\% nitric acid solution was used, followed by a deionized (DI) water rinse and ethanol wipe down. 
The "surface-smoothed" coupon was placed into a hot-rolling assembly made of low carbon steel. The assembly having a top and bottom plate, and a picture frame mid-plate, each $\sim 0.090$ in. thick (Figure 1). The inside faces of the top and bottom plates were coated with yttria spray to prevent the zirconium foil, adjacent to the alloy coupon, from adhering to the assembly during hot rolling.

Two pieces of 0.010 in. thick zirconium foil were sheared slightly larger than the coupon dimensions, so as to completely overlay the coupon's faces within the rolling assembly. The zirconium foils were cleaned with acetone prior to use and spot welded to the yttria coated cover plates, just beyond the coated area of each cover plate. After lay-up, the assembly was temporarily clamped together, moved to an argon atmosphere glove box and edge welded on all four sides.

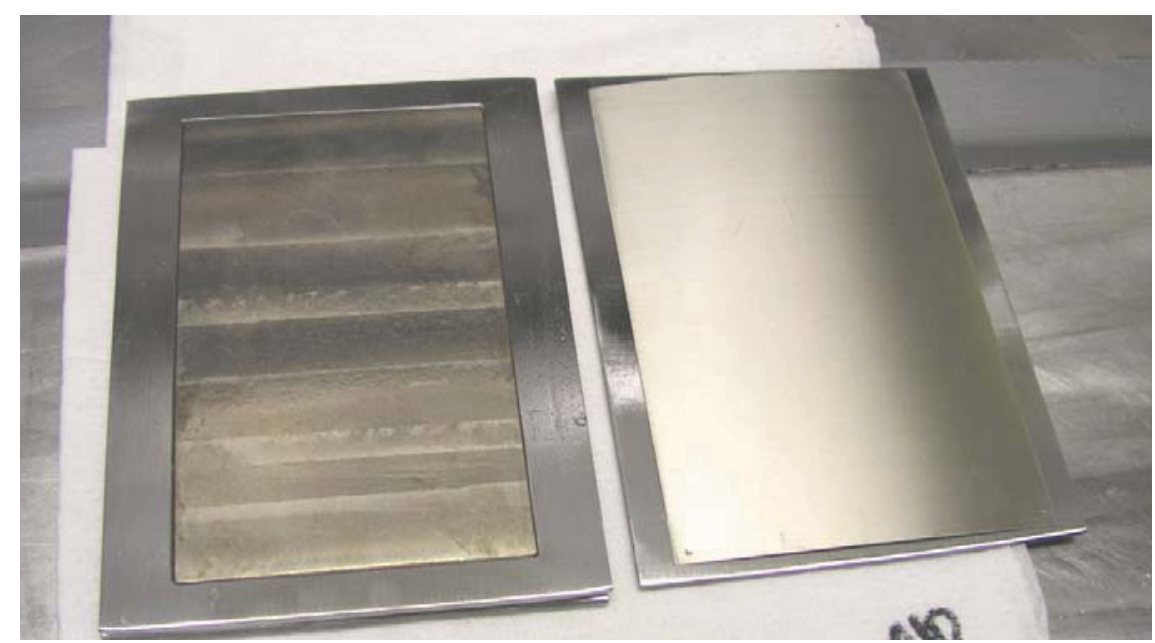

Figure 1. Image showing hot rolling assembly components prior to final lay-up and welding.

The welded rolling assembly was preheated in a box furnace for 45 minutes at $650^{\circ} \mathrm{C}$, after which the assembly was removed from the furnace using tongs and passed through a two-high rolling mill. After two passes, the assembly was returned to the furnace, reheated, and the rolling process repeated. The first four passes of the rolling schedule were conducted with the assembly/coupon rotated 90 degrees from long dimension of the coupon to increase the width of the to-be-obtained fuel foil, thus affording two AFIP-size foils to be obtained per coupon.

Figure 2 shows a graph of the rolling assembly thickness with time and maximum per pass force. Two passes per sequence are represented for each of the first nine data points. The remaining 11 data points reflect single passes made between each furnace reheat. A total of 29 rolling passes were performed. It is observed that the rolling force incrementally increases until a 30-minute reheat is performed at the 165-minute mark. Thereafter, 15-minute reheats were performed after each pass. The significant reduction in pass force after the 30 -minute reheat is due to a less-aggressive reduction, which was employed to prevent rippling of the rolling assembly/foil. 


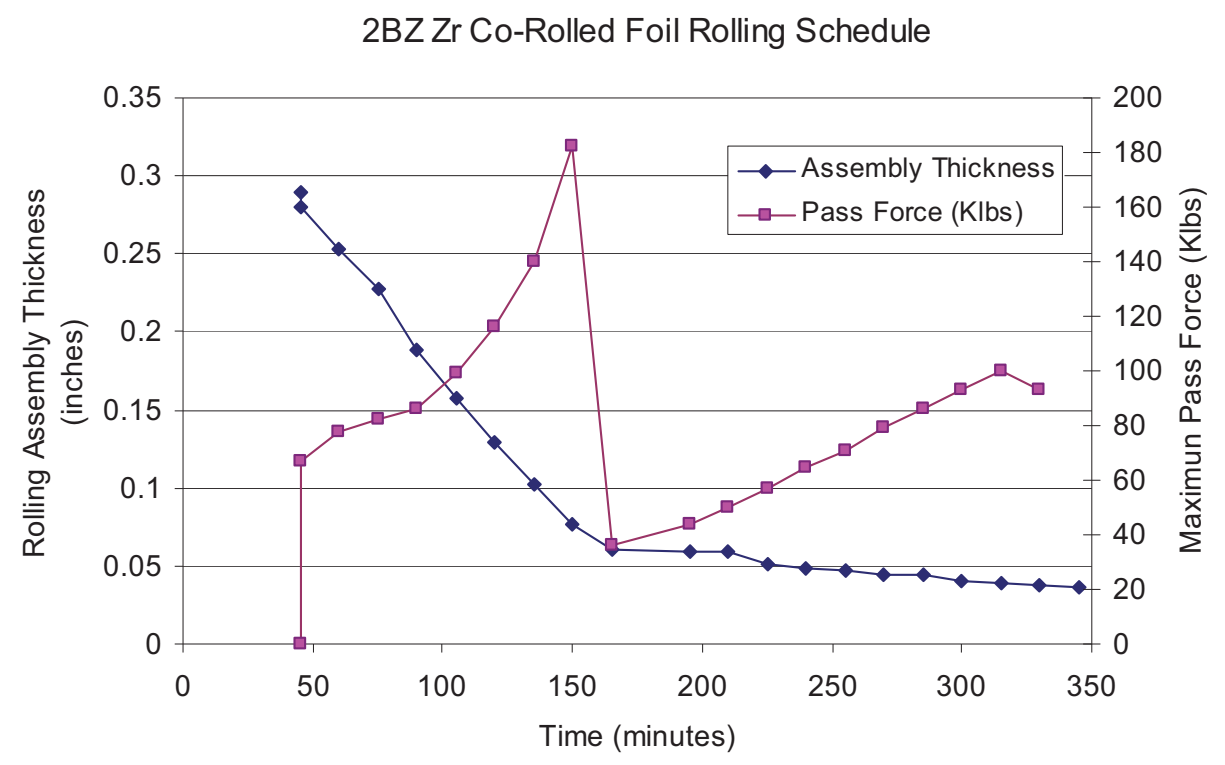

Figure 2. Graph of rolling assembly thickness and pass force throughout Zr co-rolled U10Mo foil processing.

After the rolling assembly was reduced to a thickness of 0.036 in., the $\mathrm{Zr}$ co-rolled foil, "still in the can," was annealed for 120 minutes at $650^{\circ} \mathrm{C}$. Figure 3 shows an image of the annealed rolling assembly. Subsequently, the edges of the assembly were sheared away and the foil was removed.

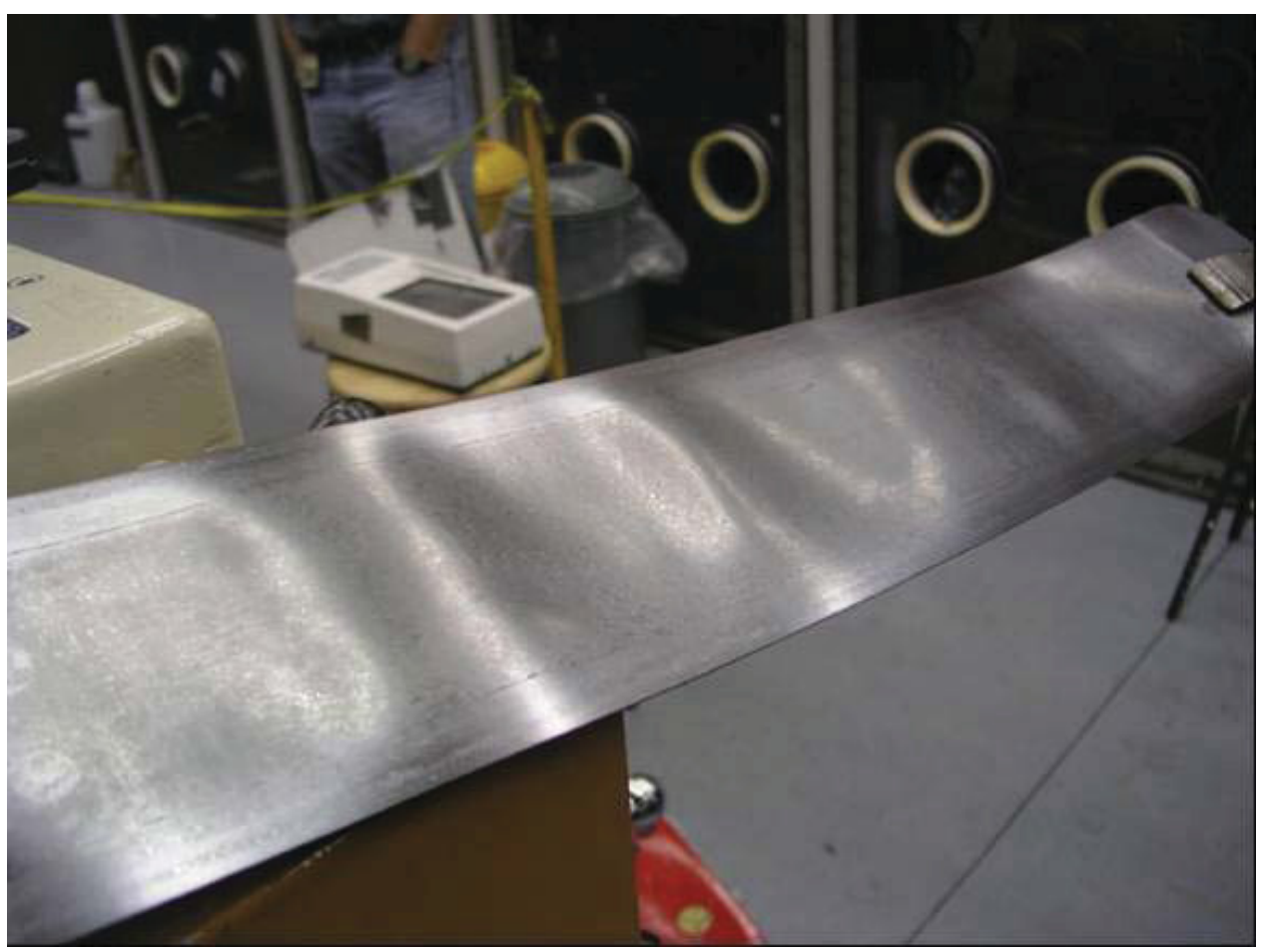

Figure 3. Hot rolling assembly post rolling and annealing, prior to foil removal. 
Prior to cladding, the $\mathrm{Zr}$ co-rolled foil was sheared to the desire size $\sim 1.5 \mathrm{in} . \times 20.5 \mathrm{in}$. and the surface cleaned on tarnish using a mixture of nitric and hydrofluoric acid $\left(\sim 2.5 \% \mathrm{HF}, \sim 35 \% \mathrm{HNO}_{3}, 62.5 \% \mathrm{H}_{2} \mathrm{O}\right)$, followed by a thorough water rinse and ethanol soak/wipe down. Figure 4 shows a picture of two AFIPsize Zr co-rolled U10Mo foils after decanning and shearing. Standard U10Mo foil (without Zr co-rolled layer) were cleaned prior to clad bonding using $\sim 35 \% \mathrm{HNO}_{3}$ solution, followed by a thorough water rinse and ethanol soak/wipe down.

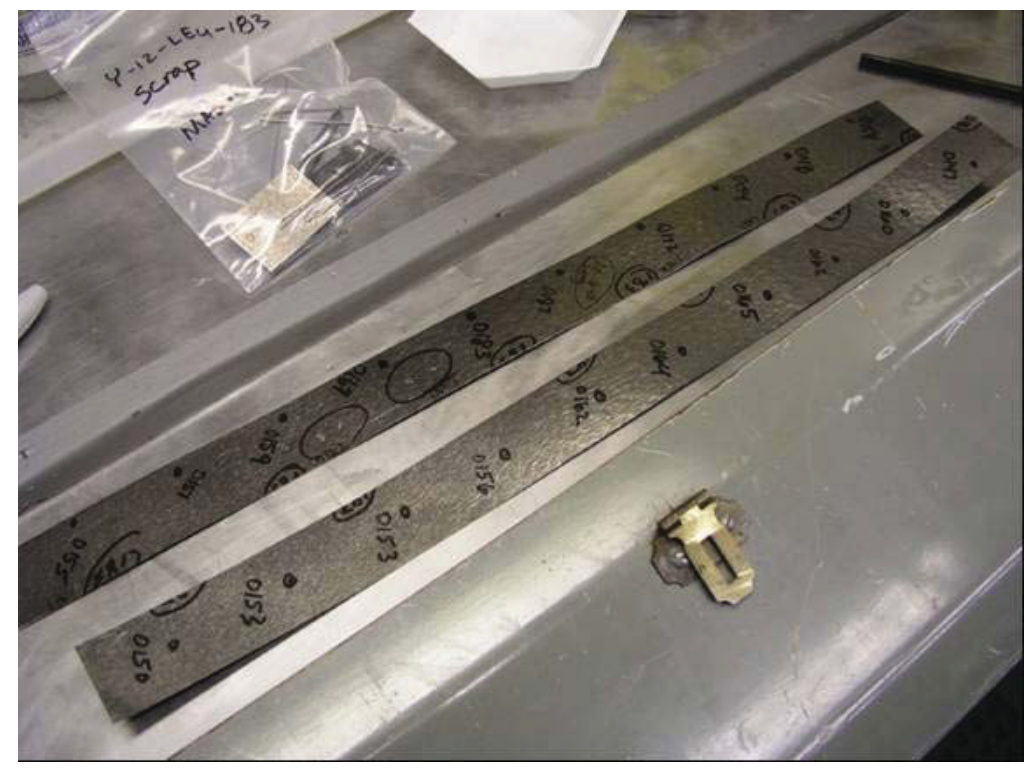

Figure 4. Sheared Zr co-rolled U10Mo fuel foil prior to cleaning.

For the foil used in 2BZ fuel plate, 33 thickness measurements were taken in three rows of eleven along the length of the foil. The average thickness was $0.0157 \mathrm{in}$., the minimum thickness was $0.0143 \mathrm{in}$. (91\% of average), and the maximum thickness was 0.0180 in. (114\% of average); these measurements include the $\sim 0.0015 \mathrm{in}$. zirconium layer on each side of the foil. These values are consistent with the densitometric fuel loading calculation discussed below; the average fuel meat "U10Mo" thickness is 0.012 in. Figure 5 shows a cross section of a U10M Zr co-rolled foil previously prepared.

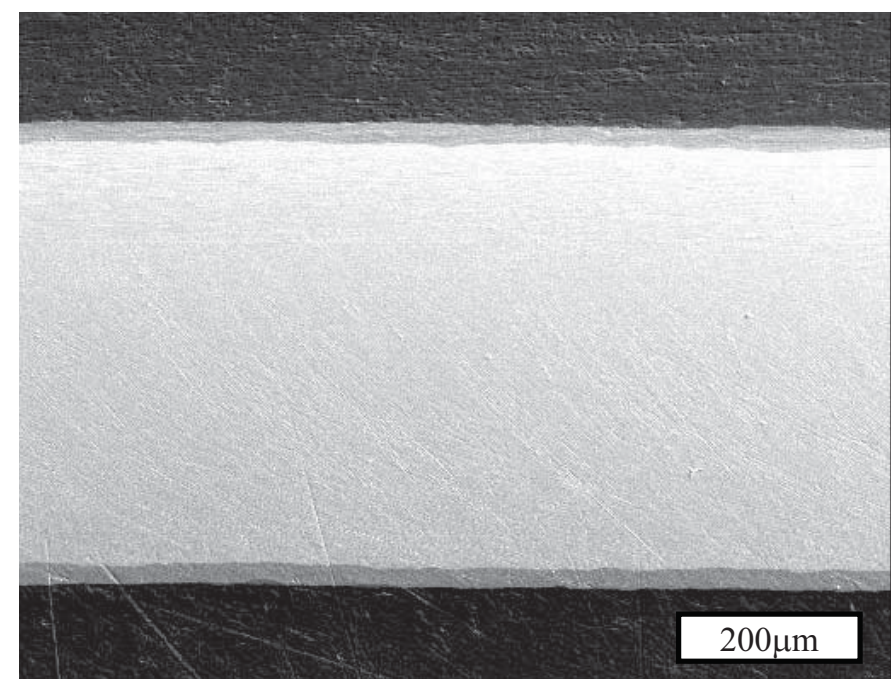

Figure 5. Cross sectional scanning electron microscope (SEM) micrograph of a nominally 0.010-in.-thick U10Mo fuel foil with $\mathrm{Zr}$ co-rolled barrier layer. 


\section{CLADDING PREPARATION}

Aluminum cladding "sets" use in the FB process were prepared as follows:

1. As received sheets of $6061-\mathrm{T} 6$, nominal thickness 0.040 in. and 0.025 in., were sheared into $\sim 8$ in. $\times$ 32 in. pieces.

2. For cladding sets designated to receive a thermal spray silicon coating, a perimeter machining step was performed so that the thermal spray coated regions "top and bottom" could be precisely aligned with the foil using two trued edges and a notched corner.

3. Both sides of each cladding sheet were brushed using a 3-in.-diameter stainless steel brush chucked in a milling machine tool holder. The brushing was performed at 340 rotations per minute $(\mathrm{rpm})$ and a feed rate of 45 in. per minute (ipm).

4. A foil retention pocket was milled into the 0.040 in. sheet material using an end mill operating at $3000 \mathrm{rpm} / 15 \mathrm{ipm}$. Both the brushing and pocket machining steps were aided by the use of a Computer Numerically Controlled (CNC) controller and vacuum chuck to hold the sheet material flat processing.

5. Brushed/machined cladding sets were chemically cleaned using a hot sodium hydroxide etching solution. The process involves the following steps described in Table 5.

Table 5. Aluminum chemical cleaning processing steps and conditions.

\begin{tabular}{|l|c|c|c|}
\hline \multicolumn{1}{|c|}{ Chemical Cleaning Step } & Method & Temp $\left({ }^{\circ} \mathrm{C}\right)$ & Time (sec) \\
\hline Degrease (Acetone/ethanol) & Hand & RT $^{*}$ & - \\
\hline Basic Etch (2M NaOH solution) & Bath & $80-85$ & $20-120$ \\
\hline Water Rinse/Desmut & Bath & RT & $15-30$ \\
\hline Desmut (sponge, cloth, or brush) & Hand & - & - \\
\hline Pickle (30\% nitric acid solution) & Bath & RT & 120 \\
\hline Water Rinse & Bath & RT & $15-30$ \\
\hline Hot Rinse & Bath & $80-85$ & $\approx 15-30$ \\
\hline Wipe (Lint Free) & Hand & - & - \\
\hline Vacuum Seal (if stored) & Hand & - & - \\
\hline * Room Temperature (RT) & & & \\
\hline
\end{tabular}

\section{THERMAL SPRAY COATING APPLICATION}

Cleaned cladding sets were prepared for silicon thermal spray coating application as follows:

1. Using a template/mask and a micro grit blaster, the area to be coated "foil pocket and opposing cladding-plate region were roughened using high purity alumina abrasive. After the surface preparation step, the plates were cleaned using a wet acetone/ethanol wipe, dried, and placed in a clean plastic bag.

2. Cladding plates were mounted in a holding fixture and a template/mask aligned and secured over the front face. A 0.001-0.002 in. silicon coating was applied using a Praxair SG-100 plasma spray gun utilizing 30 standard liters per minute (SL) of argon. The coating was formed by traversing the cladding plate in front of the thermal spray plume at $350 \mathrm{~mm} / \mathrm{sec}$. 
3. Coated cladding sets were wrapped with lint-free clothes and vacuum sealed in plastic bags until needed.

\section{FRICTION BONDING FUEL PLATE FABRICATION}

Cladding was bonded to prepared fuel foils using the Friction Bonding (FB) process developed at INL. The process involves the use of a water-cooled rotating tool configured in a Kearny \& Trecker milling machine (Figure 6).

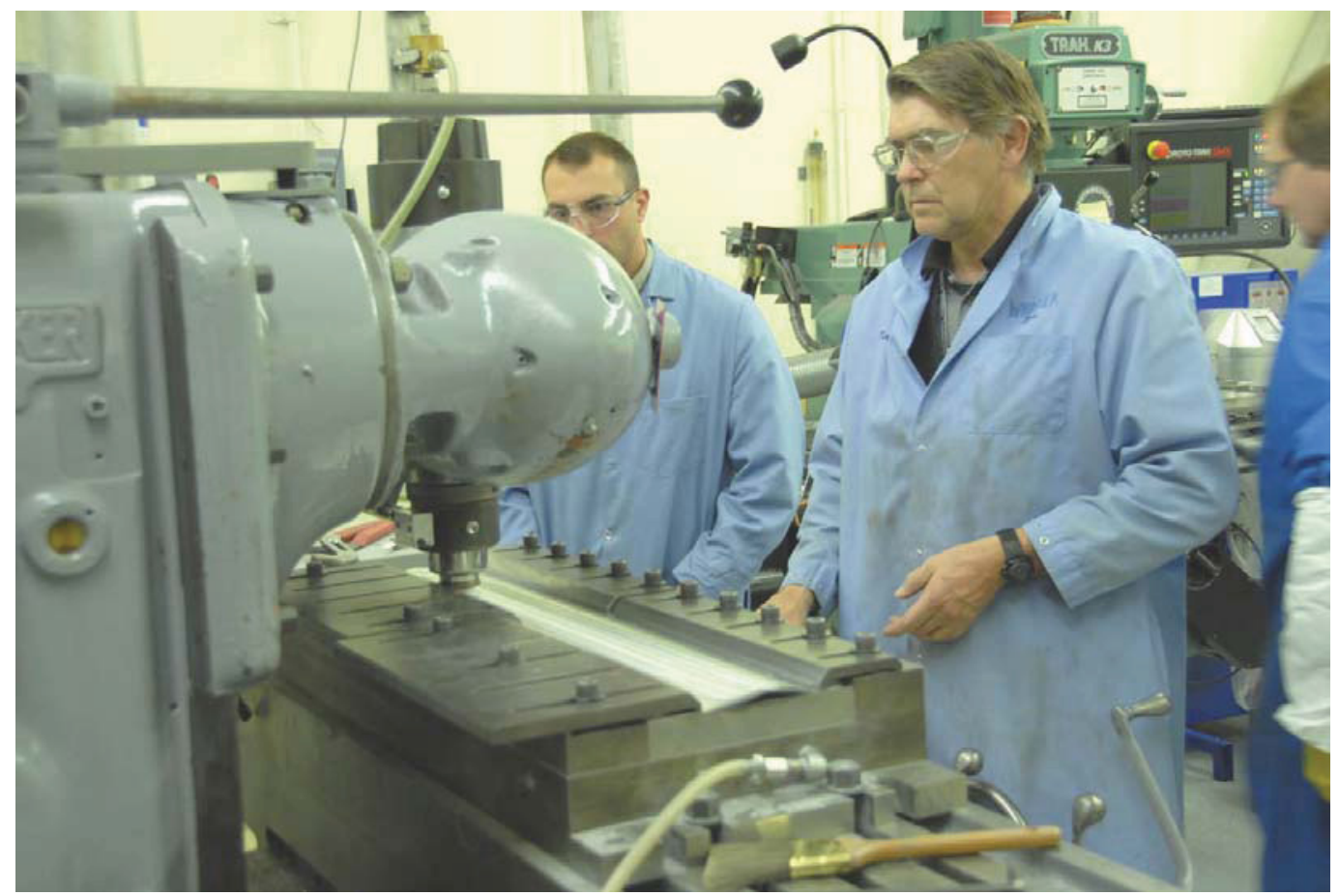

Figure 6. Friction bonding of AFIP-2 fuel plate.

A cladding/foil "pack" was prepared for the FB process by inserting a fuel foil into the machined "foil retention pocket" of the $0.040 \mathrm{in}$. thick aluminum cladding. The $0.025 \mathrm{in}$. cladding sheet "cover" was then put in place. The cladding/foil lay-up "pack" was then placed on a water-cooled anvil, located on the mill table, and clamped firmly in place along each longer edge of the pack.

Clad/Clad and Clad/Fuel bonding was accomplished via the following steps:

1. Slowly bringing the rotating tool into contact with the cladding material

2. Applying a controlled amount of down force and time to generate thermo-mechanical softening of the cladding material under the tool.

3. Traversing the work piece "clad/foil pack" per parameters listed in Table 6.

4. Stopping the traverse and drawing out the rotating tool from the work piece.

5. Returning to the start position and offsetting work piece for the next pass.

6. Removing any protruding flash material from the upcoming pass region using a scraping tool.

7. Repeating steps above until one side of fuel plate was been friction bonded.

8. Sanding and/or scraping protruding flash material from the work piece. 
9. Flipping the clad/fuel pack over and securing in the anvil.

10. Repeating the FB process on the second side.

Table 6. Friction bonding parameters used for the AFIP-2 fuel plate.

\begin{tabular}{|l|l|}
\hline Friction Bonding Process Parameter (FB-029) & Units \\
\hline Down force range & $8500-10,500 \mathrm{lb}$ \\
\hline Tool speed & $406 \mathrm{rpm}$ \\
\hline Feed rate (inches per second) & $37 \mathrm{ips}$ \\
\hline Step over distance between passes & $0.45 \mathrm{in}$. \\
\hline Number of passes per side & $\begin{array}{l}\text { First side: } 8 \\
\text { Second side: } 7\end{array}$ \\
\hline
\end{tabular}

After the FB process was completed and before the "fuel plate" was removed from the anvil, plates were rough sanded, second side only, with 80 and 160-grit sand paper in order to remove any flashing material; a source of scatter/noise when conducting UT characterization. Plates were also inscribed or stamped with an ID. After removal of the work piece from the anvil, the non-bonded cladding material, used for clamping the work piece to the anvil, was shear away.

Prior to final plate processing steps, friction-bonded fuel plates were characterized "qualitatively" for bonding and cladding thickness over the fuel zone region "min clad" using an ultrasonic testing (UT) work station. Details of UT characterization are discussed below in the Quality Assurance (QA) section.

\section{FINAL PROCESSING SEQUENCE}

Prior to final processing steps, UT characterization results and "location" radiographs were use to ascertain if any fuel foil material was disturbed during the FB process. Namely, whether the FB tool clipped the fuel foil, and subsequently created and relocated fuel foil fragments. Also, to establish if sufficient cladding thickness was available to perform final finishing steps.

Based on a map of the plate thickness, established using micrometer measurements, and the thickness of cladding above the fuel foil, as recognized with UT characterization, the fuel plate was sanded on both sides in order to create a fuel plate having the desired overall thickness $(0.050 \pm 0.003)$, and a minimum cladding thickness of 0.006 in. over the fuel foil.

Once sanding of a fuel plate was completed, the location of the fuel zone relative to the coursesheared fuel plate perimeter was determined using of a location radiograph. Next, with the aid of fuel plate drawing transparency/template, the final plate/foil position was marked, and the fuel plate was sheared to near final size, which left $\sim 0.063$ in. additional material around the perimeter. Sheared material was collected for subsequent bend testing, with the location of each piece recorded and the edge nearest the fuel plate marked.

The fuel plate was next machined to the final size using a milling machine configured with an end mill tool operating at $1200 \mathrm{rpm}$ and 7 ips. A plate identification engraving was also applied $-\sim 0.005$ in. in depth.

Location radiographs were obtained in support if the Fuel out of Zone (FOZ) Inspection discussed below. 


\section{OXIDE COATING APPLICATION}

An oxide film "beohmite" was applied to the fuel plate using an autoclave treatment. Prior to autoclaving, fuel plates were chemically cleaned using the sodium hydroxide solution etching process described above, including the nitric acid pickle and water rinse steps. Approximately $0.0005-0.001$ in. of cladding thickness is removed with cleaning and a like thickness reestablished after autoclaving.

Two fuel plates were fully immersed in deionized water within the autoclave, with only their edges in contact with the plate holder. The oxide film was then applied using a 4-hour hold at $185^{\circ} \mathrm{C}$ and pressure of $\sim 160$ psi. Figure 7 below shows the autoclave time-temperature-pressure conditions.

Following the oxide film treatment, immersion density measurements were obtained in order to acquire fuel plate volume. Subsequently, final dimensional inspection, final UT characterization, and a cleanliness inspection were performed.

$2 \mathrm{TT} / 2 \mathrm{BZ}$ A utoclave S chedule

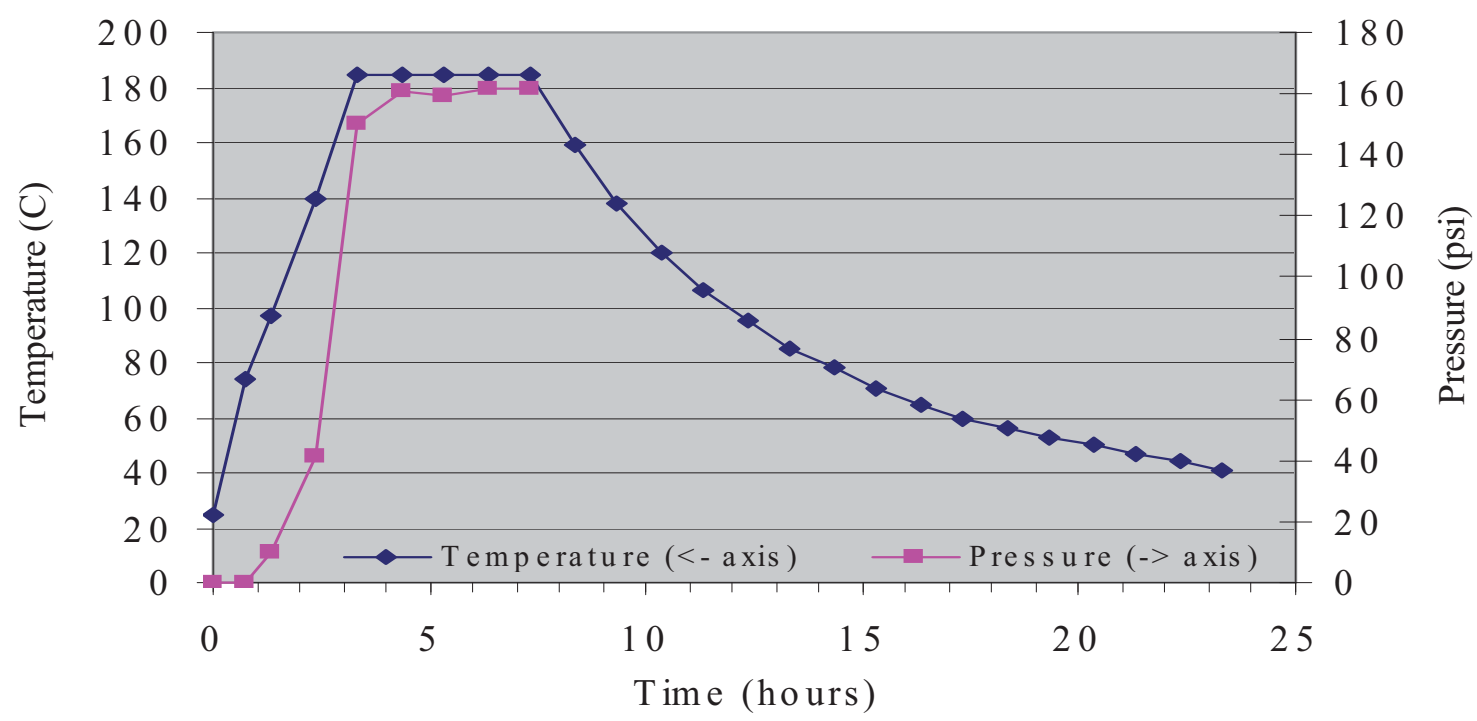

Figure 7. Autoclave schedule for AFIP-2 Fuel plates.

\section{FUEL PLATE ASSEMBLY}

The two fuel plates that qualified for the AFIP-2 experiment, 2TT and 2BZ, were mounted end-to-end in the Fuel Plate Frame Assembly, as shown in INL Drawing 635789. Figure 8, shows a composite image of the loaded AFIP-2 fuel plate frame assembly. Note that the plates are tack welded in place, on each side, near the midpoint of the 48.75-in.-long frame.

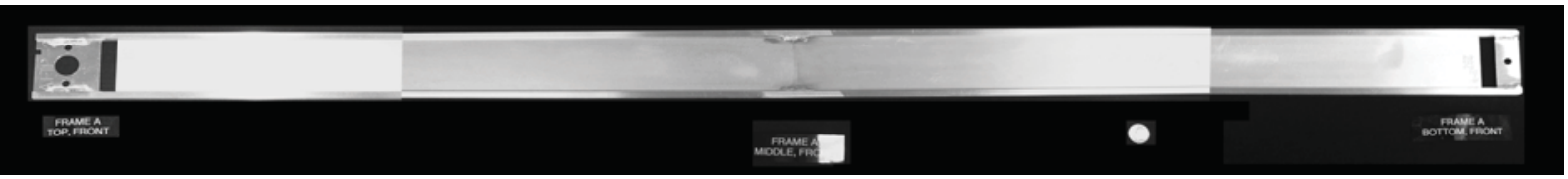

Figure 8. Composite image of AFIP-2 Experiment Fuel Plate Frame Assembly. 


\section{FUEL PLATE QUALITY ASSURANCE}

\subsection{Fuel Loading}

This section summarizes fuel loading calculations performed for AFIP-2 fuel plates 2TT and 2BZ. A more detailed description of the fuel loading calculations can be found in INL ECAR-132, "Fuel Loading Calculations for AFIP-2 Irradiation Experiment."

Candidate fuel plates were submitted to the MFC QA services for radiography. Radiographs were taken in the presences of a U8Mo tab-based reference standard, and densitometric measurements were acquired by qualified MFC QA personnel per TFR-491 "Fuel Plate Specification for the AFIP-2 Fuel Irradiation in the ATR." The densitometric data obtained were used to perform fuel loading calculations and establish if the fuel plates met the fuel loading acceptance criteria established. Namely, the maximum allowable calculated thickness at any data point was 0.022 in. The maximum allowable Average Calculated Thickness for the overall plate was 0.016 in. (Table 7).

Table 7. Summary of fuel loading acceptance criteria and AFIP-2 plate data.

\begin{tabular}{|l|c|}
\hline \multicolumn{1}{|c|}{ Fuel Loading Criteria } & Thickness (in) \\
\hline Maximum Allowable Calculated Thickness (each data point) & 0.022 \\
\hline Maximum Allowable Average Calculated Thickness (each plate) & 0.016 \\
\hline AFIP-2 Plate Data & Thickness (in) \\
\hline Maximum Calculated Thickness for fuel plate sample: 2TT & 0.015 \\
\hline Average Calculated Thickness for fuel plate sample: 2TT & 0.014 \\
\hline Maximum Calculated Thickness for fuel plate sample: 2BZ & 0.016 \\
\hline Average Calculated Thickness for fuel plate sample: 2BZ & 0.012 \\
\hline
\end{tabular}

Both candidate fuel plates, $2 \mathrm{TT}$ and 2BZ, were determined to have no fuel loading regions above the Maximum Allowable Calculated Thickness (for each data point acquired) and an average fuel loading below the Maximum Allowable Average Thickness; as per TFR-491 Section 5.3.4 "Fuel Loading."

The following section discusses the densitometric data collection process and the fuel loading calculation performed.

\subsection{Collection and Processing of Densitometric Data}

Given the size of each fuel plate's fuel zone (20.5 in,), a three-shot exposure scenario (left, middle, and right; $\sim 10$ in. long for each zone) was applied to each candidate fuel plate. The plates were marked with tungsten index markers to facilitate an indexed three-exposure data set to be obtained (Figure 9). A multi tab U8Mo density standard was placed in each exposure. From each radiograph, 60 densitometric data points were obtained (three rows of 20 , taken along the center line of the fuel foil and at $0.5 \mathrm{in}$. to each side, starting at $\sim 0.25$ in. from the end of the fuel foil); see densitometric data acquisition map in Figure 9. Five densitometric readings were taken of each density standard tab within the 1-4 optical density (OD) range. The X-rite densitometer used was configured with a $3 \mathrm{~mm}$ aperture. A second order polynomial was fit to the "standard data" to establish the mathematical relationship between the film density of the "standard's tabs" and that of the corresponding fuel foil. 


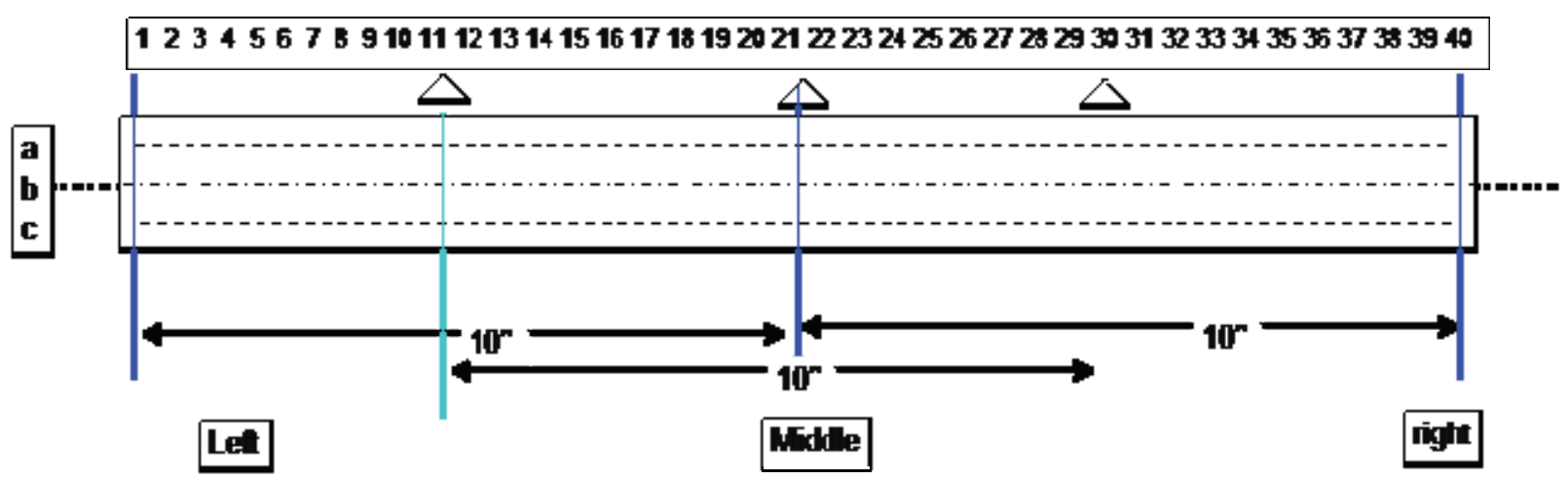

Figure 9. Densitometric data acquisition map showing exposure and data collection scheme used for AFIP-2 fuel plates.

The average fuel zone thickness was calculated based on the "left" and "right" data sets. The maximum fuel loading was established based on all three data sets (left, middle, and right). The reference standard data tab range was established based on the available OD readings within the range of 1 to 4; resulting in nine data point sets, encompassing a U8Mo thickness range of 0.008 to 0.025 in. thickness (Figure 10). The fit equation parameters were recorded and the $\mathrm{R}^{\wedge} 2$ trendline parameter, in all cases, was at 0.98 or greater.

Du8Mo Standard Data, LEFT SIDE Radiograph, (Foil 183/Plate 2BZ)

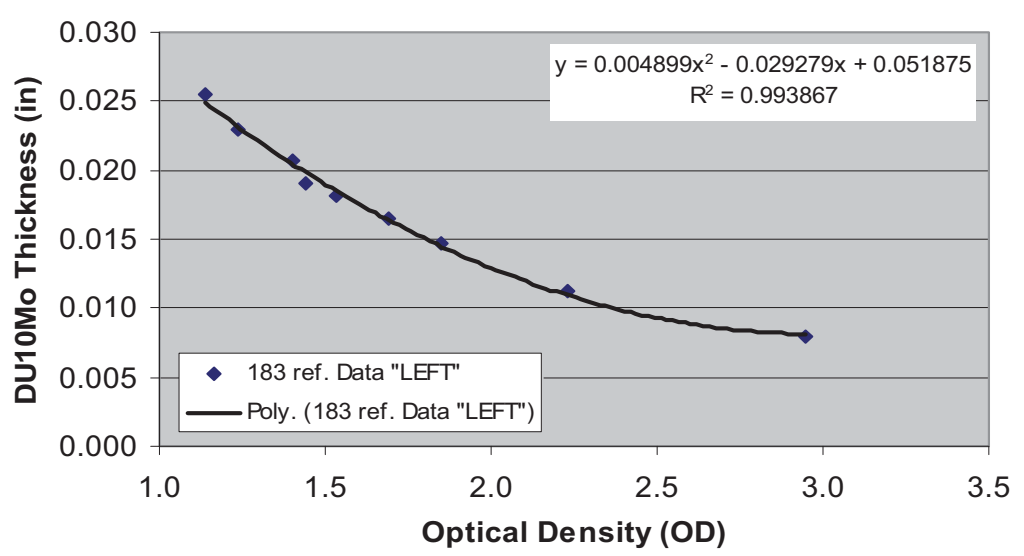

Figure 10. Example of Du8Mo standard data set plot and fit equation.

Utilizing the second order polynomial fit parameters, the acquired fuel zone densitometric readings were converted to an equivalent U8Mo thickness. The equivalent thickness value was subsequently adjusted for the density " $\rho$ " and compositional difference between the standard (U8Mo) and the fuel foil alloy (U10Mo), an adjustment factor of 103.21\% (Table 8).

Table 8. Summary of fuel loading thickness data for AFIP-2 fuel plates.

\begin{tabular}{|c|c|c|c|}
\hline \multirow{2}{*}{ Fuel Plate } & \multicolumn{3}{|c|}{ Calculated Thickness } \\
\cline { 2 - 4 } & Average (in.) & Minimum (in.) & Maximum (in.) \\
\hline 2TT & 0.014 & 0.013 & 0.015 \\
\hline 2BZ & 0.012 & 0.010 & 0.016 \\
\hline
\end{tabular}


Figures 11 and 12 below show a plot of the aggregate calculated U10Mo fuel foil thickness values calculated for the three exposure data set or each fuel plate; fuel specification allowable maximum average thickness is references as a dashed line at 0.016 in. on the y-axis, and the "any point maximum thickness is references as a solid grey line at 0.022 in. on the y-axis.

AFIP-2 Fuel Plate 2TT (Foil 175)

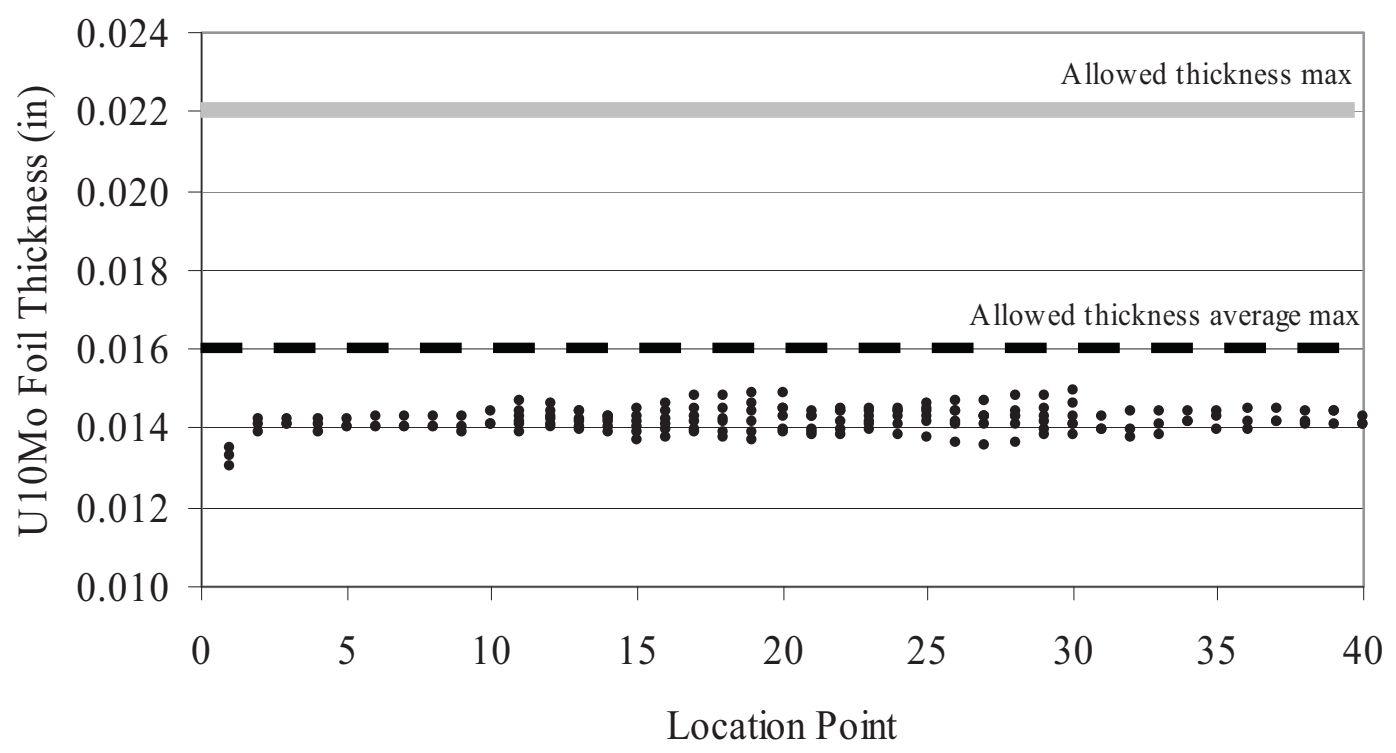

Figure 11. Plot of calculated U10Mo thickness values for AFIP-2 fuel plate 2TT.

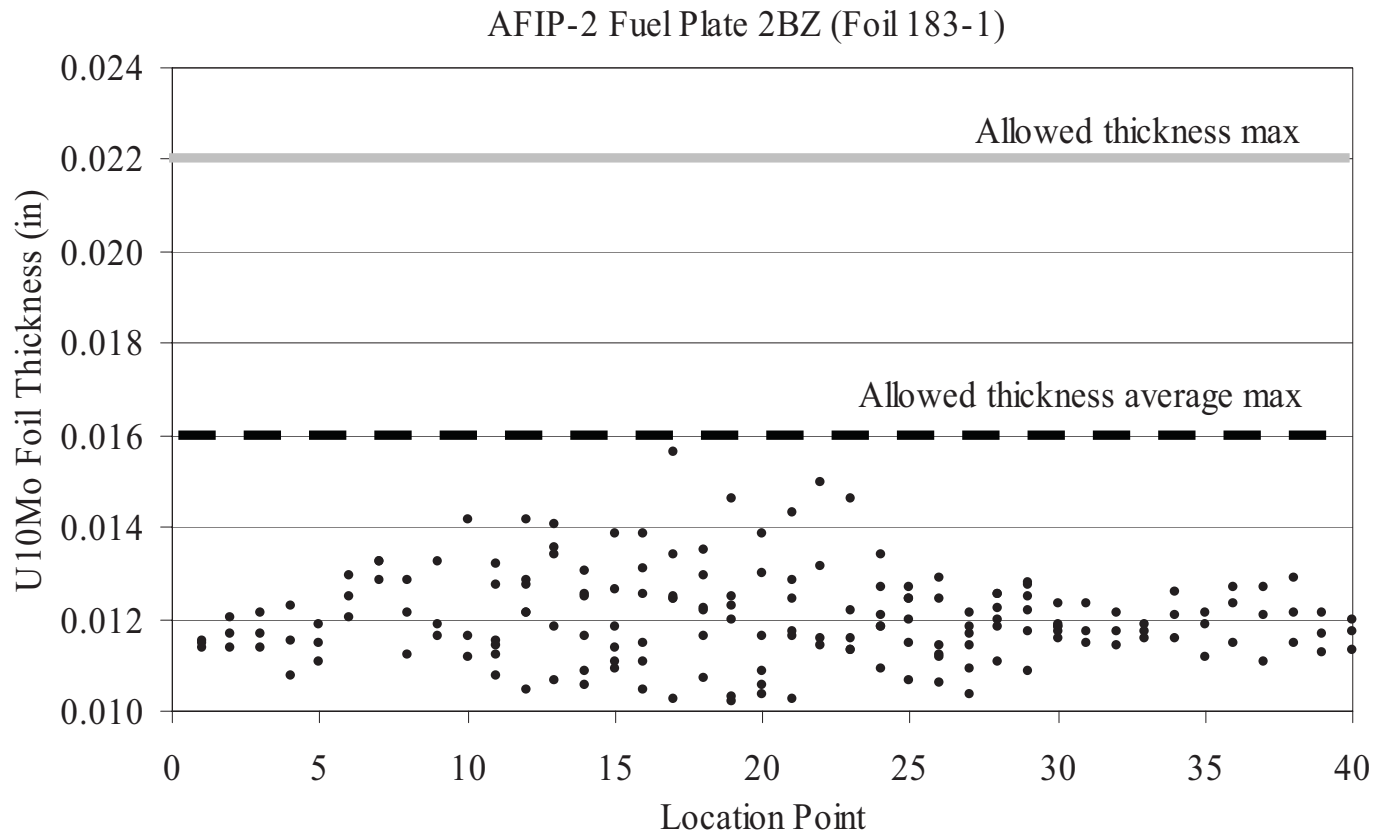

Figure 12. Plot of calculated U10Mo thickness values for AFIP-2 fuel plate 2BZ. 


\subsection{Ultrasonic Testing (UT) Characterization}

This section summarizes the results of the ultrasonic inspection/evaluation of AFIP-2 fuel plates 2TT and 2BZ. A more detailed description of the UT characterization results can be found in TEV-411, "AFIP-2 Fuel Plates Ultrasonic Debond, Minclad Thickness, and Irradiated Plate Thickness Test Results."

The UT workstation at INL MFC-787 consists of a water tank, sample holder, UT scanning hardware, and a data acquisition system (Figure 13). The data acquisition system used was a standards based inspection/evaluation system. Two types of scans are acquired: (1) Debond Scan that yields a single image/maps of ultrasonic signal transmission through a sample, and (2) Min Clad Scan that yields a series of images, via time-of-fight analysis/process of back reflections, representative of "reflection features" at a given depth from each face (near and far) of a sample. Reflection features arise from interfaces, inclusion, and/or voids. Both types of scans can be acquired simultaneously.

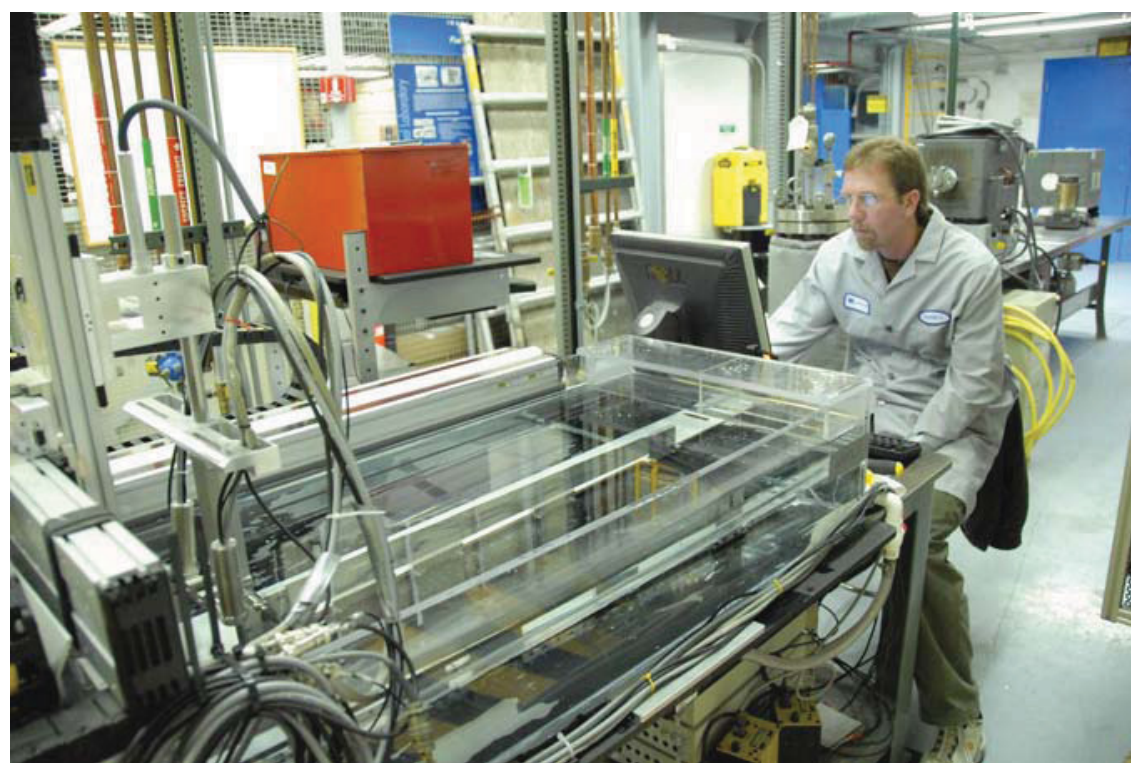

Figure 13. UT characterization workstation at INL MFC-787.

The Debond image/data was considered "for information only," but acquired using a calibrated system. Figure 14, shows the Debond scan images for the 2TT and 2BZ fuel plates. Areas/points lacking significant transmission (typically 50\%) are referred to as "indications." An indication was defined as "a response of or evidence from a discontinuity in a material" and may or may not be cause for rejection of a sample going through the established qualification process.

Calibrated reference standards were used to validate the system both before and after the inspection/evaluation. The Minclad inspection data was used for acceptance of meeting the fuel specification requirement for minimum cladding. Namely, per the fuel specification: "The cladding thickness above the fuel zone region of each fuel plate shall be determined using UT characterization. Each fuel plate shall be subjected to a minimum cladding UT scan. Traceable references standards are used to verify the minclad system calibration before and after the fuel plate was characterized. The minclad standard was an aluminum plate having engineered voids with known depths and diameters. Specifications for minimum cladding requirements are stated in INL Drawing 635788." Per INL Drawing 635788 , the minimum cladding thickness callout was as 0.006 in. 
When describing information obtained from UT characterization/analysis, near side and far side reference was made relative to plate orientation in the UT tank; it was administratively established that a fuel plate sample was mounted for characterization with the ID stamp on the front (loading side) and right side of the established sample holder (thus the "front side of the plate" having the plate ID engraving was designated as the "near side" and the non-engraved side of the fuel plate was references and the "far side")

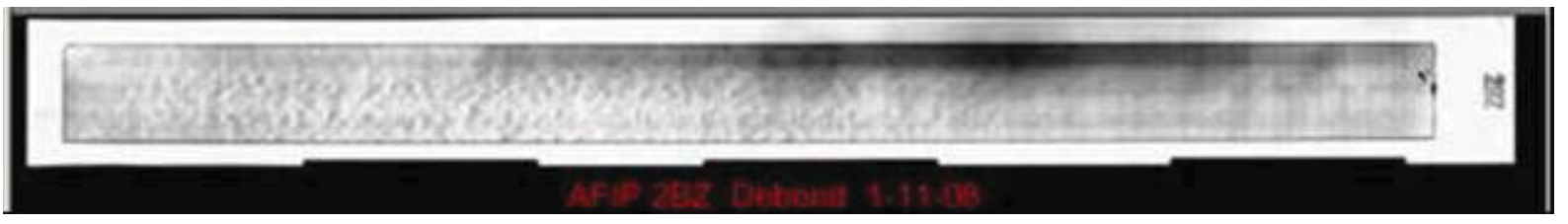

2BZ

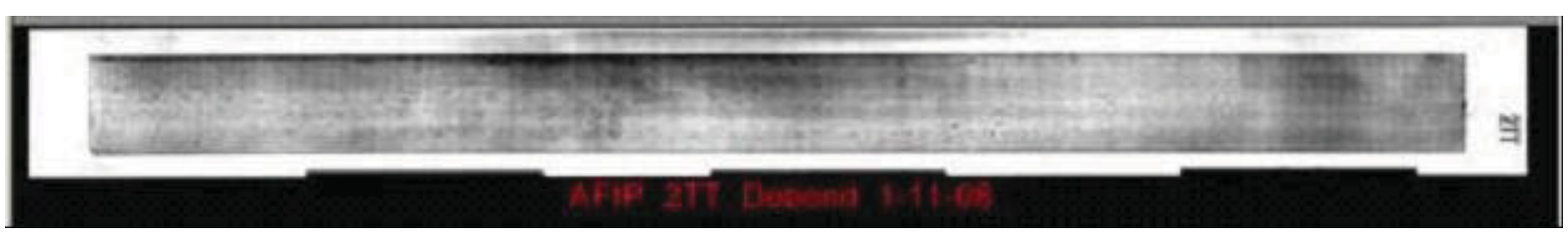

$2 \mathrm{TT}$

Figure 14. Debond scan images of AFIP-2 fuel plates.

\subsection{Plate 2TT UT Characterization Summary}

One $\sim 0.01$-in.-diameter pit located on the non-ID end of Plate 2TT was noted during the visual examinations. Ultrasonic clad thickness measurements were made on the near side of the plate, which indicated $0.017 \mathrm{in}$. of clad near the pit. Given that the pit depth was $0.0023 \mathrm{in}$. deep, the cladding thickness underlying the region was established to be 0.0147 in.

\section{Plate 2TT}

Minclad: Near side minimum clad thickness: 0.007 in.

Minclad Far side minimum clad thickness: 0.012 in.

Debond: Small indications, approximately 0.07 by 0.13 in., were noted across the length of the plate with a larger indication at the ID end of the plate.

General plate surface conditions: Numerous minor surface artifacts show in the debond data, but are not to be considered minclad violations or debonds.

\section{Plate 2BZ}

Minclad: Near side minimum clad thickness: 0.007 in.

Minclad Far side minimum clad thickness: 0.008 in.

Debond: Small debond indications, approximately $0.060 \times 0.210$ in., were noted across the length of the plate with some larger indications at the ID end of the plate. No indications were identified in the "perimeter region" defined by the INL drawing. 
General plate surface conditions: Numerous minor surface indications on both the near side and the far side of the plate. Also numerous artifacts show in the data, but are not to be considered minclad violations or debonds unless noted as such.

Stray Fuel Particles: Stray fuel particles were noted in 2TT radiographs. Clad thickness over the stray fuel particles varies with each fuel particle. Three particles were ultrasonically evaluated. On the near side indications varied between $0.007 \mathrm{in}$. and $0.021 \mathrm{in}$. Clad thickness varies between $0.026 \mathrm{in}$. and $0.036 \mathrm{in}$. on the far side.

Both candidate fuel plates,2TT and 2BZ, meet the acceptance criteria established for minimum cladding and debond indications; per TFR-491, "Fuel Plate Specification for the AFIP-2 Fuel Irradiation in the ATR."

\subsection{Fuel Out of Zone Inspection}

FOZ inspection was employed for the purpose of insuring that any stray particles outside of the maximum fuel region and plate edges and ends, as defined in INL Drawing 635788, do not violate established acceptance criteria for use in the ATR reactor. Specifically, stray fuel particles are allowed provided they do not violate the following:

- One or more stray fuel particles, which fit in a square $0.5 \mathrm{~mm} \times 0.5 \mathrm{~mm}$ was acceptable and

- The stray fuel particle(s), which fit in the $0.5 \mathrm{~mm} \times 0.5 \mathrm{~mm}$ square, was/are no closer than $2 \mathrm{~mm}$ to any other $0.5 \mathrm{~mm} \times 0.5 \mathrm{~mm}$ square of particles edge to edge. and

- No stray fuel particle was closer to the plate edge or end than the major dimension of the particle.

The FOZ inspection was conducted by a qualified Inspector using a 5x magnifier, a transparency template of the fuel plate perimeter and maximum fuel zone, and radiograph(s) of the fuel plate acquired using conditions that yield high contrast of the fuel material and showing the plate's perimeter.

Both fuel plates for the AFIP-2 experiment met the FOZ acceptance requirements.

\subsection{Dimensional, Surface, and Cleanliness Inspection}

The dimensional and surface inspection was conducted by a qualified inspector and per INL Drawing 635788, which establishes that a candidate fuel plates meets (or not) the dimensional specifications established for length, width, and thickness. The minimum and maximum values of each dimension are recorded, as well as 30 thickness measurement values for future use in establishing irradiated plate swelling. This data is recorded on the Fuel Plate Summary Sheet for each fuel plate, see Appendixes A and $\mathrm{B}$ of this document

The criteria established for the visual cleanliness inspection are as follows:

"Surface defects: such as scratches, marks, grooves, pores and other surface flaws greater than $0.203 \mathrm{~mm}$ (0.008 in.) deep, inside the maximum fuel zone, shall be cause for rejection (using a template)."

Both fuel plates for the AFIP-2 experiment met the established dimensional, surface, and cleanliness inspection requirements.

\subsection{Bend Testing and Bend Test Sample Inspection}

Bend testing was utilized to insure that the FB process produces a complete aluminum-aluminum bond of the cladding material around the perimeter of the fuel zone region. 
The bend test consists of the following steps:

- Acquiring samples from all sides of each plate. At least 12 bend samples adjacent to each plate (including five along each long side and one along each short side).

- Marking the samples such that the edge nearest the fuel plate was established.

- Clamping each sample in a test fixture and bending the sample around a $\sim 0.125$ in. radius/mandrel 90 degrees from the starting position, then returning the sample to the initial position, then bending the sample 90 degrees in the other direction, and lastly, bending the sample back to the original position.

- Visually inspecting bend test samples, by a qualified inspector, for any visual delamination of the edge indicated as adjacent to the fuel plate.

All bend test samples, for both fuel plates qualified for the AFIP-2 experiment, 2TT and 2BZ, met the acceptance criteria of the bend test inspection performed.

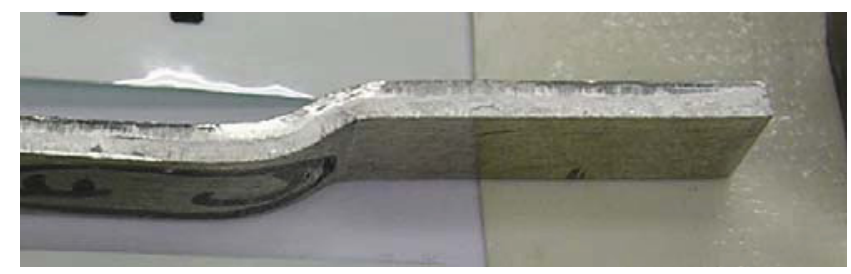

No Delamination

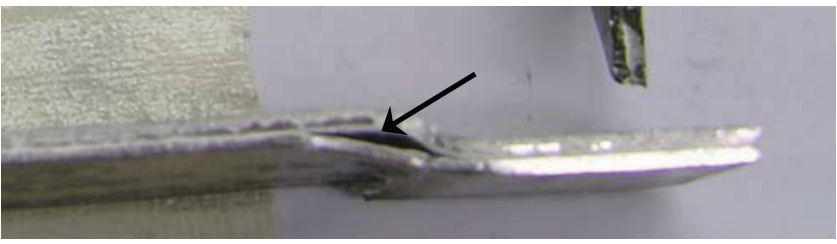

Delamination

Figure 15. Example of bend testing sample delamination.

\subsection{Radiological Release}

Prior to loading fuel plates in the test frame assembly, radiological smears were taken from both fuel plates. Smears were counted for signs of radiological surface contamination.

Both AFIP-2 fuel plates, 2BZ and 2TT, showed no detectable radiological contamination and were "free released" and assembled in the AFIP-2 fuel plate assembly.

\subsection{Quality Assurance Data Review}

Qualification of fuel plate samples is accomplished by the preparation of an As-Built Data Package, which contains documentation for each Fuel Specification required data/quality element (Table 9). After review by the project quality engineer, a "Green Tag" is issued for each qualifying sample. Green tags accompany the samples from the fabrication facility to the Advanced Test Reactor (ATR). 
Table 9. As-Built Data Package content list.

\begin{tabular}{|l|}
\hline \multicolumn{1}{|c|}{ As-Built Data Package Content List } \\
\hline QA Checklist \\
\hline Materials Certifications \\
\hline Plate Summary Sheet \\
\hline Alloying Activity Sheet \\
\hline Uranium Cleaning Activity Sheet \\
\hline Alloy Tracking Spreadsheet \\
\hline Foil Cleaning and Final Dimensions Activity Sheet \\
\hline Thermal Spray Coating Activity Sheet \\
\hline Friction Bonding Data Sheet \\
\hline Immersion Density Activity Sheet \\
\hline Dimensional and Surface Inspection Report \\
\hline Bend Tests Sample Inspection Report \\
\hline Fuel out of Zone (FOZ) Inspection Report \\
\hline Dimensional Inspection Report \\
\hline Autoclave Run Record \\
\hline Ultrasonic Characterization (UT) document reference \\
\hline Fuel Loading document reference \\
\hline Radiological Survey \\
\hline Assembly Loading Documentation \\
\hline Assembly Welding Documentation \\
\hline Non-Conformance Reports (NCRs) \\
\hline
\end{tabular}

\section{REFERENCES}

Company-Controlled Documents

ECAR-132, Fuel Loading Calculations for AFIP-2 Irradiation Experiment

ECAR-144, AFIP-2 Ultrasonic Debond and Clad Thickness Test Results

INL Rec./Doc. ID 2600687, RERTR AFIP-2 Irradiation Experiment in the ATR, As-Built Data Package

PLN-2688, Experiment Control Plan for the AFIP-2 Fuel Irradiation in the ATR

TFR-491, Fuel Plate Specification for the AFIP-2 Fuel Irradiation in the ATR 


\section{Appendix A}

\section{BZ Plate Summary Sheet}




\section{Appendix A}

\section{BZ Plate Summary Sheet}

\section{AFIP-2 Monolithic Plate Summary Sheet \\ Monolithic Plate: 2BZ (AFIP-2, Frame Position: Bottom, Co-rolled Zr)}

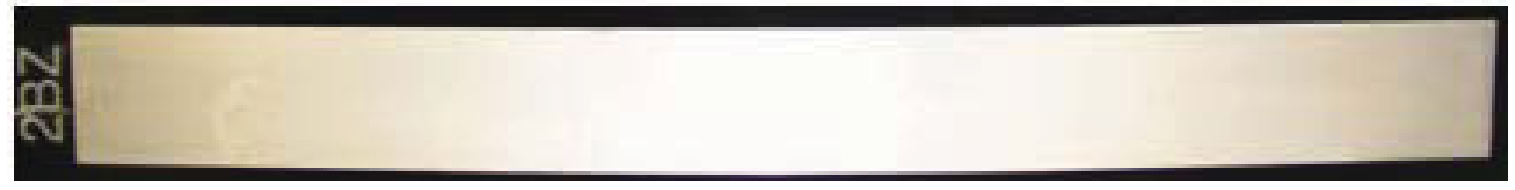

Monolithic Plate Description "nominal":

Uranium Molybdenum Fuel Alloy: U10Mo $\pm 0.5 \mathrm{wt} \% \mathrm{Mo}$

Uranium Enrichment: $19.75 \mathrm{wt} \% \mathrm{U}$ enrichment $\pm 1 \mathrm{wt} \%$

Fuel Meat Thickness: 0.014 in.

Cladding: 6061 aluminum

Other: Clad bonding via Friction Bonding process; 0.001 in. thick Zirconium (Zr) layer applied to foil via hot rolling process on both sides of foil.

\begin{tabular}{|c|c|c|c|c|c|c|}
\hline \multicolumn{7}{|c|}{ Monolithic Plate Data } \\
\hline Plate Mass (g) & Fuel Foil Mass (g) & U-235 (g) & U-238 (g) & U-Total (g) & Mo (g) & Zr (g) \\
\hline 202.829 & 108.711 & 17.809 & 71.771 & 89.580 & 10.272 & 8.859 \\
\hline
\end{tabular}

\begin{tabular}{|l|c|}
\hline \multicolumn{2}{|c|}{ Uranium Alloy (U-10Mo) } \\
\hline Fuel: U-10Mo (Y-12 Batch: 3C19-WY-M9TH) Foil-183 & U10Mo Mass (g) \\
\hline EU-10 Mo SPM\#: 140-20-60831-00000 & 99.852 \\
\hline
\end{tabular}

\begin{tabular}{|c|c|c|c|}
\hline \multicolumn{4}{|c|}{ Foil Composition } \\
\hline Zr (wt\%) Barrier & Mo (wt\%) & U (wt\%) & U-Enrichment (wt\%U) \\
\hline & 10.21 & 89.714 & 19.881 \\
\hline 8.15 & \multicolumn{2}{|c|}{91.85} & \\
\hline
\end{tabular}

\begin{tabular}{|l|l|c|}
\hline \multicolumn{2}{|c|}{ Non-Fuel Materials } \\
\hline \multicolumn{1}{|c|}{ Material } & \multicolumn{1}{|c|}{ Use Description } & FASB Nos \\
\hline Al-6061 & Cladding “Cover Plate" & 33 \\
\hline Al-6061 & Cladding "Bottom Plate" & 32 \\
\hline Zr Foil (99.995\%) metal basis & Zirconium "Barrier Layer" & 103 \\
\hline
\end{tabular}




\begin{tabular}{|c|c|c|c|}
\hline \multicolumn{4}{|c|}{ Fuel Foil Dimensions(in-process measurement) } \\
\hline Foil Length (in.) & Foil Width (in.) & 33 Pt. Average Foil Thickness (in.) (in-process) \\
\hline \multirow{2}{*}{20.623} & \multirow{2}{*}{1.465} & Average with Zr Clad & 0.0157 \\
\cline { 3 - 4 } & & Estimated Average without Zr Clad & 0.0137 \\
\hline
\end{tabular}

\begin{tabular}{|c|c|c|c|}
\hline \multicolumn{4}{|c|}{ Fuel Plate Dimensions } \\
\hline Plate Length (in.) & Plate Width (in.) & Plate Thickness (in.) & Plate Volume (in. ${ }^{3}$ ) \\
\hline Max: 22.496 & Max: 2.2145 & Max: 0.0527 & Geometric: 2.588 \\
\hline Min: 22.495 & Min: 2.2115 & Min: 0.05030 & Immersion: 2.568 \\
\hline
\end{tabular}

\begin{tabular}{|c|c|c|c|}
\hline \multicolumn{4}{|c|}{ Fabrication Roll-Down } \\
\hline Y-12 Coupon ID & RERTR Foil ID & Friction Bonding Run & Plate ID \\
\hline 3C19-WY-M9TH & 183 & FB-29/FSW-29 & 2BZ \\
\hline
\end{tabular}




\section{AFIP-2 Monolithic Plate Summary Sheet}

\section{Monolithic Plate: 2BZ (AFIP-2, Frame Position: Bottom, Co-rolled Zr)}

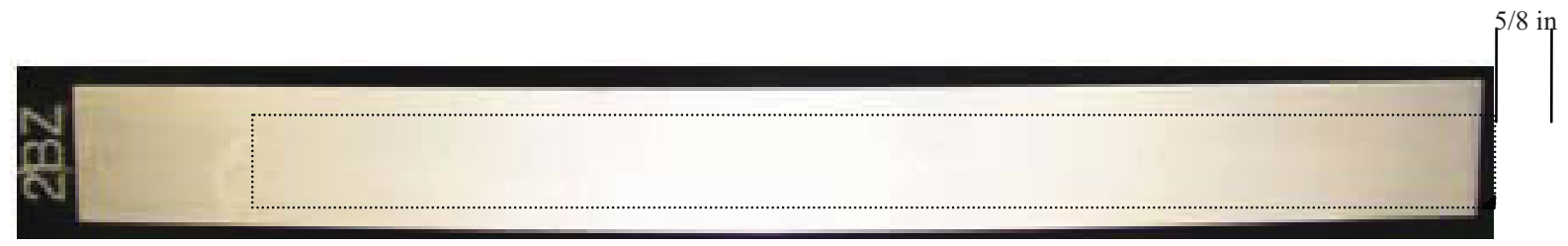

Plate Thickness Measurement Map:

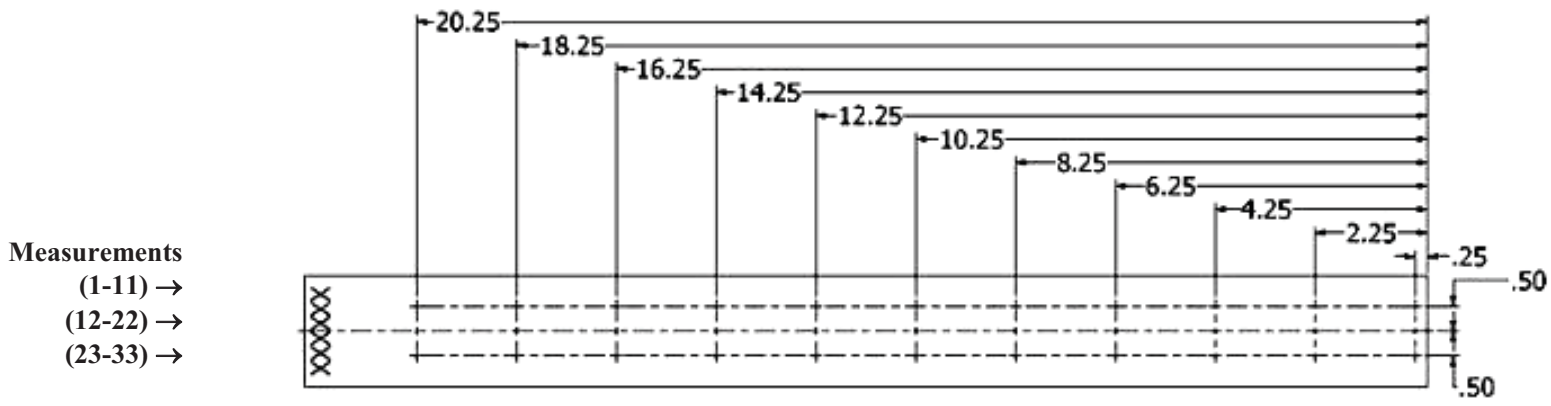

Plate Thickness Measurements (in) "QC Inspector Measurements”:

\begin{tabular}{|c|c|c|c|c|c|c|c|c|c|c|}
\hline $\mathbf{1}$ & $\mathbf{2}$ & $\mathbf{3}$ & $\mathbf{4}$ & $\mathbf{5}$ & $\mathbf{6}$ & $\mathbf{7}$ & $\mathbf{8}$ & $\mathbf{9}$ & $\mathbf{1 0}$ & $\mathbf{1 1}$ \\
\hline 0.0521 & 0.0524 & 0.0520 & 0.0525 & 0.0526 & 0.0523 & 0.0526 & 0.0526 & 0.0514 & 0.0503 & 0.0521 \\
\hline $\mathbf{1 2}$ & $\mathbf{1 3}$ & $\mathbf{1 4}$ & $\mathbf{1 5}$ & $\mathbf{1 6}$ & $\mathbf{1 7}$ & $\mathbf{1 8}$ & $\mathbf{1 9}$ & $\mathbf{2 0}$ & $\mathbf{2 1}$ & $\mathbf{2 2}$ \\
\hline 0.0518 & 0.0514 & 0.0516 & 0.0522 & 0.0510 & 0.0523 & 0.0526 & 0.0522 & 0.0524 & 0.0504 & 0.0518 \\
\hline $\mathbf{2 3}$ & $\mathbf{2 4}$ & $\mathbf{2 5}$ & $\mathbf{2 6}$ & $\mathbf{2 7}$ & $\mathbf{2 8}$ & $\mathbf{2 9}$ & $\mathbf{3 0}$ & $\mathbf{3 1}$ & $\mathbf{3 2}$ & $\mathbf{3 3}$ \\
\hline 0.0520 & 0.0515 & 0.0527 & 0.0518 & 0.0520 & 0.0526 & 0.0522 & 0.0522 & 0.0520 & 0.0520 & 0.0518 \\
\hline
\end{tabular}

\section{Foil Thickness Measurement Map:}

Measurements

$(11-1) \rightarrow$

(22-12) $\rightarrow$

(33-23) $\rightarrow$

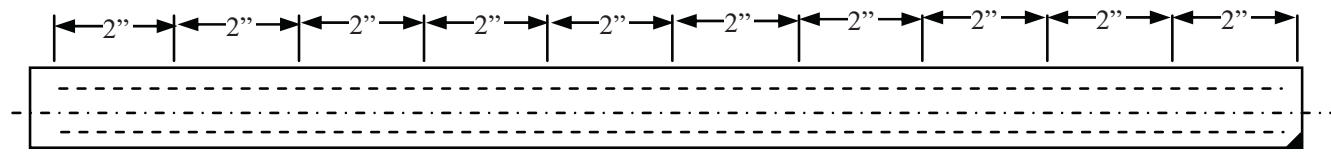

Foil Thickness Measurements* (in) "In-Process Measurements":

\begin{tabular}{|c|c|c|c|c|c|c|c|c|c|c|}
\hline 11 & 10 & 9 & 8 & 7 & 6 & 5 & 4 & 3 & 2 & 1 \\
\hline 0.0147 & 0.0146 & 0.0148 & 0.0153 & 0.0169 & 0.0166 & 0.0170 & 0.0165 & 0.0153 & 0.0146 & 0.0143 \\
\hline 22 & 21 & 20 & 19 & 18 & 17 & 16 & 15 & 14 & 13 & 12 \\
\hline 0.0150 & 0.0146 & 0.0150 & 0.0156 & 0.0159 & 0.0180 & 0.0171 & 0.0152 & 0.0163 & 0.0152 & 0.0147 \\
\hline 33 & 32 & 31 & 30 & 29 & 28 & 27 & 26 & 25 & 24 & 23 \\
\hline 0.0156 & 0.0152 & 0.0153 & 0.0155 & 0.0165 & 0.0170 & 0.0166 & 0.0168 & 0.0161 & 0.0160 & 0.0151 \\
\hline
\end{tabular}


Appendix B

2TT Plate Summary Sheet 


\section{Appendix B}

\section{TT Plate Summary Sheet}

\section{AFIP-2 Monolithic Plate Summary Sheet \\ Monolithic Plate: 2TT (AFIP-2, Frame Position: Top, Thermal Spray)}

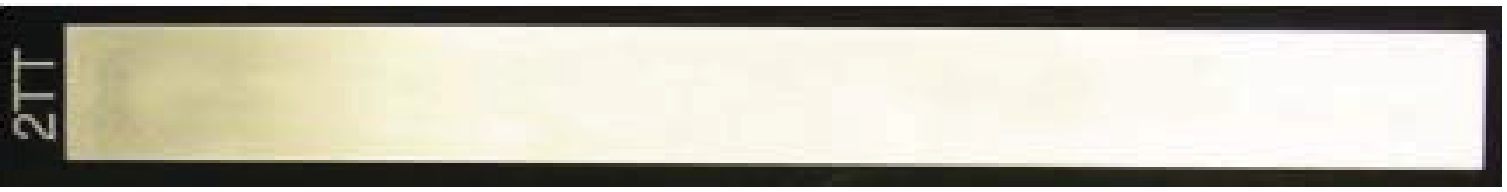

Monolithic Plate Description "nominal":

Uranium Molybdenum Fuel Alloy: U10Mo $\pm 0.5 \mathrm{wt} \% \mathrm{Mo}$

Uranium Enrichment: 19.75 wt $\%$ U enrichment $\pm 1 \mathrm{wt} \%$

Fuel Meat Thickness: 0.014 in.

Cladding: 6061 aluminum

Other: Clad bonding via Friction Bonding process; $\sim 0.001$ in. thick Silicon (Si) thermal spray layer applied to cladding above and below fuel foil location.

\begin{tabular}{|c|c|c|c|c|c|}
\hline \multicolumn{7}{|c|}{ Monolithic Plate Data } \\
\hline Plate Mass (g) & Fuel Foil Mass (g) & U-235 (g) & U-238 (g) & U-Total (g) & Mo (g) \\
\hline 204.511 & 109.186 & 19.474 & 78.481 & 97.955 & 11.231 \\
\hline
\end{tabular}

\begin{tabular}{|l|c|}
\hline \multicolumn{2}{|c|}{ Uranium Alloy (U-10Mo) } \\
\hline Fuel: U-10Mo (Y-12 Batch: 3C19-WY-M9T9) Foil-175 & U10Mo Mass (g) \\
\hline EU-10 Mo SPM: 140-20-6-824-00000 & 109.186 \\
\hline
\end{tabular}

\begin{tabular}{|c|c|c|}
\hline \multicolumn{3}{|c|}{ Foil Composition } \\
\hline Mo (wt\%) & U (wt\%) & U-Enrichment (wt\%) \\
\hline 10.21 & 89.714 & 19.881 \\
\hline
\end{tabular}

\begin{tabular}{|l|l|c|}
\hline \multicolumn{2}{|c|}{ Non-Fuel Materials } \\
\hline \multicolumn{1}{|c|}{ Material } & \multicolumn{1}{|c|}{ Use Description } & FASB \#s \\
\hline Al-6061 & Cladding "Cover Plate" & 33 \\
\hline Al-6061 & Cladding "Bottom Plate" & 32 \\
\hline $\mathrm{Si}$ & Thermal Spray Powder (Barrier Layer) & 98 \\
\hline
\end{tabular}

Fuel Foil Dimensions (in-process measurement)

\begin{tabular}{|c|c|c|}
\hline Foil Length (in.) & Foil Width (in.) & 33 Pt. Average Foil Thickness (in.) \\
\hline 20.540 & 1.473 & 0.013 \\
\hline
\end{tabular}




\begin{tabular}{|c|c|c|c|}
\hline \multicolumn{3}{|c|}{ Fuel Plate Dimensions } \\
\hline Plate Length (in.) & Plate Width (in.) & Plate Thickness (in.) & Plate Volume (in. ${ }^{\mathbf{3}}$ ) \\
\hline Max: 22.500 & Max: 2.2145 & Max: 0.0525 & Geometric: 2.56 \\
\hline Min: 22.496 & Min: 2.2100 & Min: 0.0501 & Immersion: 2.54 \\
\hline
\end{tabular}

\begin{tabular}{|c|c|c|c|}
\hline \multicolumn{4}{|c|}{ Fabrication Roll-Down } \\
\hline Y-12 Foil ID & RERTR Foil ID & Friction Bonding Run & Plate ID \\
\hline 3C19-WY-M9T9 & 175 & FB-28/FSW-28 & 2TT \\
\hline
\end{tabular}




\section{Monolithic Plate: 2TT (AFIP-2, Frame Position: Top, Thermal Spray)}

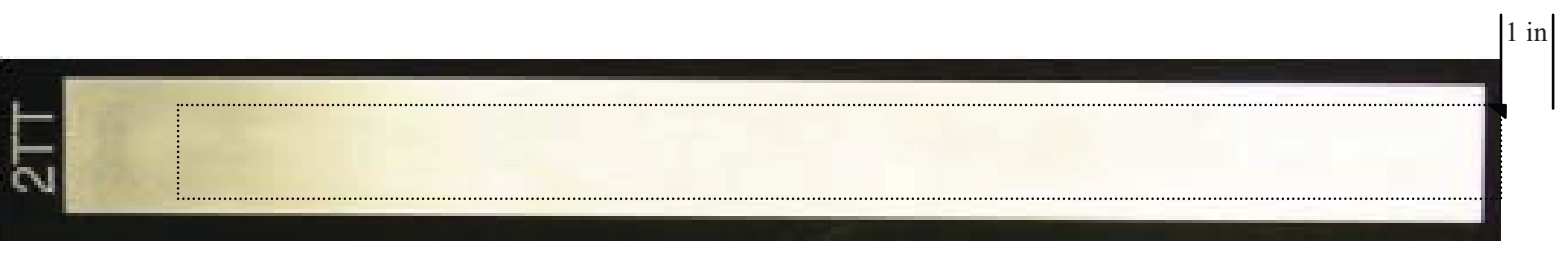

Plate Thickness Measurement Map:

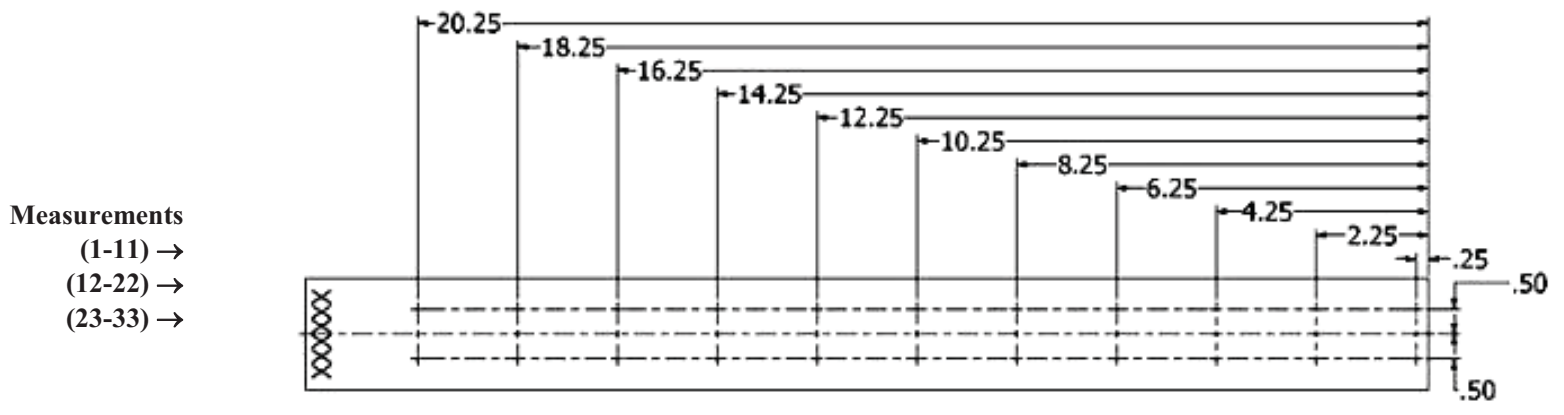

Plate Thickness Measurements (in) "QC Inspector Measurements":

\begin{tabular}{|c|c|c|c|c|c|c|c|c|c|c|}
\hline $\mathbf{1}$ & $\mathbf{2}$ & $\mathbf{3}$ & $\mathbf{4}$ & $\mathbf{5}$ & $\mathbf{6}$ & $\mathbf{7}$ & $\mathbf{8}$ & $\mathbf{9}$ & $\mathbf{1 0}$ & $\mathbf{1 1}$ \\
\hline 0.0515 & 0.0520 & 0.0520 & 0.0507 & 0.0516 & 0.0525 & 0.0522 & 0.0520 & 0.0513 & 0.0511 & 0.0514 \\
\hline $\mathbf{1 2}$ & $\mathbf{1 3}$ & $\mathbf{1 4}$ & $\mathbf{1 5}$ & $\mathbf{1 6}$ & $\mathbf{1 7}$ & $\mathbf{1 8}$ & $\mathbf{1 9}$ & $\mathbf{2 0}$ & $\mathbf{2 1}$ & $\mathbf{2 2}$ \\
\hline 0.0501 & 0.0509 & 0.0518 & 0.0506 & 0.0509 & 0.0517 & 0.0522 & 0.0518 & 0.0512 & 0.0512 & 0.0523 \\
\hline $\mathbf{2 3}$ & $\mathbf{2 4}$ & $\mathbf{2 5}$ & $\mathbf{2 6}$ & $\mathbf{2 7}$ & $\mathbf{2 8}$ & $\mathbf{2 9}$ & $\mathbf{3 0}$ & $\mathbf{3 1}$ & $\mathbf{3 2}$ & $\mathbf{3 3}$ \\
\hline 0.0504 & 0.0511 & 0.0520 & 0.0514 & 0.0512 & 0.0512 & 0.0515 & 0.0512 & 0.0512 & 0.0509 & 0.0518 \\
\hline
\end{tabular}

\section{Foil Thickness Measurement Map:}
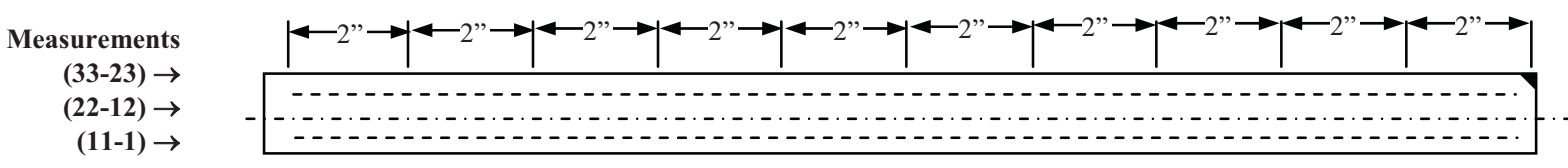

Foil Thickness Measurements (in) "In-Process Measurements":

\begin{tabular}{|c|c|c|c|c|c|c|c|c|c|c|}
\hline $\mathbf{3 3}$ & $\mathbf{3 2}$ & $\mathbf{3 1}$ & $\mathbf{3 0}$ & $\mathbf{2 9}$ & $\mathbf{2 8}$ & $\mathbf{2 7}$ & $\mathbf{2 6}$ & $\mathbf{2 5}$ & $\mathbf{2 4}$ & $\mathbf{2 3}$ \\
\hline 0.0128 & 0.0130 & 0.0127 & 0.0126 & 0.0127 & 0.0128 & 0.0128 & 0.0128 & 0.0128 & 0.0129 & 0.0130 \\
\hline $\mathbf{2 2}$ & $\mathbf{2 1}$ & $\mathbf{2 0}$ & $\mathbf{1 9}$ & $\mathbf{1 8}$ & $\mathbf{1 7}$ & $\mathbf{1 6}$ & $\mathbf{1 5}$ & $\mathbf{1 4}$ & $\mathbf{1 3}$ & $\mathbf{1 2}$ \\
\hline 0.0131 & 0.0132 & 0.0131 & 0.0131 & 0.0128 & 0.0129 & 0.0130 & 0.0131 & 0.0131 & 0.0133 & 0.0131 \\
\hline $\mathbf{1 1}$ & $\mathbf{1 0}$ & $\mathbf{9}$ & $\mathbf{8}$ & $\mathbf{7}$ & $\mathbf{6}$ & $\mathbf{5}$ & $\mathbf{4}$ & $\mathbf{3}$ & $\mathbf{2}$ & $\mathbf{1}$ \\
\hline 0.0132 & 0.0131 & 0.0128 & 0.0131 & 0.0130 & 0.0128 & 0.0130 & 0.0128 & 0.0130 & 0.0132 & 0.0132 \\
\hline
\end{tabular}

